\title{
Surfactant-like peptides: from molecular design to controllable self-assembly with applications
}

DOI:

10.1016/j.ccr.2020.213418

\section{Document Version}

Accepted author manuscript

Link to publication record in Manchester Research Explorer

\section{Citation for published version (APA):}

Lu, J. R., Xu, H., Wang, J., Zhao, Y., Li, J., Carter, J., Waigh, T., \& Zhou, P. (2020). Surfactant-like peptides: from molecular design to controllable self-assembly with applications. Coordination Chemistry Reviews, 421(213418). https://doi.org/10.1016/j.ccr.2020.213418

\section{Published in:}

Coordination Chemistry Reviews

\section{Citing this paper}

Please note that where the full-text provided on Manchester Research Explorer is the Author Accepted Manuscript or Proof version this may differ from the final Published version. If citing, it is advised that you check and use the publisher's definitive version.

\section{General rights}

Copyright and moral rights for the publications made accessible in the Research Explorer are retained by the authors and/or other copyright owners and it is a condition of accessing publications that users recognise and abide by the legal requirements associated with these rights.

\section{Takedown policy}

If you believe that this document breaches copyright please refer to the University of Manchester's Takedown Procedures [http://man.ac.uk/04Y6Bo] or contact uml.scholarlycommunications@manchester.ac.uk providing relevant details, so we can investigate your claim.

\section{OPEN ACCESS}




\title{
Surfactant-like peptides: from molecular design to controllable self-assembly with applications
}

Jie Li ${ }^{a}$, Jiqian Wang ${ }^{\mathrm{a}, *}$, Yurong Zhao ${ }^{\mathrm{a}}$, Peng Zhou ${ }^{\mathrm{a}}$, Jessica Carter ${ }^{\mathrm{b}}$, Zongyi Li ${ }^{\mathrm{b}}$, Thomas A.

\author{
Waigh $^{\mathrm{b}}$, Jian R. Lu ${ }^{\mathrm{b}, *}$, Hai Xu ${ }^{\mathrm{a}, *}$
}

${ }^{a}$ State Key Laboratory of Heavy Oil Processing and the Centre for Bioengineering and Biotechnology,

China University of Petroleum (East China), 66 Changjiang West Road, Qingdao 266580, China

${ }^{\mathrm{b}}$ Biological Physics Group, School of Physics and Astronomy, The University of Manchester, Manchester M13 9PL, United Kingdom 


\section{Abstract}

The diversity of naturally occurring amino acids endows even a very short peptide with an incredible range of sequences, nanostructures and properties. Short peptide sequences have been widely exploited in molecular self-assembly, and this area of research has not only led to a wide range of ordered structures and nanomaterials but also provided insights into protein folding. Conversely, the general physical principles of protein folding accumulated over the past 55 years can be applied to the design of peptide self-assembly. De novo designed surfactant-like peptides (SLPs) are structurally akin to conventional surfactants, with several consecutive hydrophobic amino acids composing their hydrophobic tail region and one or two charged residues making up the hydrophilic head group. Due to their short length, well-defined hydrophobic and hydrophilic regions, innate molecular amphiphilicity, and excellent water solubility, their self-assembly and applications can be orchestrated through molecular design and varying solution conditions. With the canonical 20 amino acids as a starting point, this review introduces the physical principles dictating peptide self-assembly. Then, the major design rules for SLPs, including amino acid substitution, sequence variation, peptide length, amino acid chirality, and incorporation of specific amino acids or sequences, are described, followed by recent advances in their applications for cell culture, antibacterial and anticancer treatments, drug delivery and controlled release, biomimetic mineralization and nanofabrication, hemostasis, and membrane protein stabilization. Finally, a brief outlook to future challenges and opportunities is provided. We hope this review provides a panoramic sketch of SLPs and will inspire more effort into their fundamental research and exploitation. Keywords: peptide self-assembly, amphiphilic peptide, surfactant-like peptide, non-covalent 
interaction, molecular design, biotechnological application, bionanomaterials 


\section{Introduction}

Over the past decade, molecular self-assembly has been a highly active area of research across many scientific disciplines including chemistry, physics, material science, engineering, and biology. Furthermore, research interests in this multidisciplinary area are expanding. Indeed, self-assembly is ubiquitous in nature and common in living organism, and many biological assemblies and their structure-function relationships have provided a rich source of inspiration for scientists and engineers in this regard. Proteins are one of the most fascinating examples of self-assembly, since if a specific synthetic job is to be done in biology it is almost invariably a protein that does it $[1,2]$. To date, an incredible variety of functions in living organisms have been found to be executed by proteins, such as structural support, the catalysis of metabolic reactions, chemical storage and transportation, cell signaling and recognition, cell movement and muscle contraction, defense and protection. The diverse functional versatility of proteins is due to their intricate but ordered structures, which are often achieved by the proper folding and packing of polypeptides after biosynthesis and are driven largely by non-covalent interactions. However, if proteins become misfolded, serious health and medical conditions may occur and examples include some devastating neurodegenerative disorders, e.g., Alzheimer's, Parkinson's, prion diseases and type II diabetes [3-5]. These diseases impose major threats to human life and welfare. Inspired by natural protein architectures, along with concomitant biological functions and malfunctions, extensive efforts have been devoted to the assembly of proteins and peptides, aimed at not only unveiling the underlying mechanism of their folding and misfolding but also the fabrication of novel nanodevices and nanomaterials with ordered structures and designer 
functionalities.

Since Anfinsen's groundbreaking work in protein folding (Anfinsen's dogma) [6,7], there have been a considerable number of research articles, reviews, and books garnered in this area. For the readers who are interested in protein folding, we recommend Alan Fersht's book entitled Structure and Mechanism in Protein Science: A Guide to Enzyme Catalysis and Protein Folding [8]. Although it remains a grand challenge to accurately predict the structures of proteins and their propensity to aggregate from a known sequence [9], some general rules have been deduced over the past 55 years, such as the physical driving forces, basic conformational units ( $\alpha$-helices, $\beta$-sheets, $\beta$-turns, and coiled coils), and the structural and sequence similarity (homology), which have in turn advanced our ability to design peptideand protein-based structures and materials. Useful surveys of protein self-assembly can be found in two recent reviews by Liu et al., in which various supramolecular strategies for the construction of protein superstructures have been outlined, based on naturally occurring interactions such as those due to receptors with ligands, electrostatic, metal-coordination and non-natural hosts with guest molecules [10,11]. To introduce these specific interactions between protein monomers, either surface modifications of proteins or the addition of inducers (highly charged nanoparticles and surfactants, and synthetic ligands) are generally required [10-16]. Owing to the structural complexity, innate structural instability, and high surface heterogeneity of the majority of proteins, however, these chemical and physical treatments have been largely limited to specific types of proteins, which typically have robust native structures and well-defined morphologies. Baker et al. have recently taken advantages of advances in computational methods to design protein-protein interfaces that involve many 
noncovalent interactions [17-19]. This work could lead to the controllable assembly of proteins. Furthermore, despite considerable advances in recombinant protein production by transgenic organisms, the availability of limited amounts of active proteins, their purity and prohibitive cost still restrict studies on protein self-assembly for technological applications.

Short peptides can significantly mitigate the problems inherent with their larger counterparts. First, relative to proteins and long polypeptides, short peptides are much more stable and robust as building blocks, thus facilitating further chemical and biological modifications [20,21]. Second, short lengths allow rapid and effective production of custom-made peptides with high purity at a reasonable cost via commercial solid-phase peptide synthesis methods; advances in synthetic methodologies will make the scale-up production economically feasible in the short term. Third, due to their short lengths, the properties of self-assembling short peptides can be finely orchestrated through molecular design from scratch and the underlying mechanisms of their self-assembly can also be well understood. Fourth, owing to the variety of available amino acids (including the 20 natural amino acids and many non-natural ones), the number of possible primary structures is astonishingly large for even short peptide fragments. For example, there are $6^{20}$ possible sequences for hexapeptides, just based on the 20 naturally occurring amino acids. As a consequence, this huge combinational space provides a rich reservoir of building blocks for the exploration of peptide self-assembly. Finally, some short peptides constitute the active sites or act as the functional core of fragments of proteins, such as the well-known RGD motif for cell adhesion and movement [22], cleavable sequences for matrix metalloproteinase (MMP) degradation [23], and core fragments of amyloid-related proteins and polypeptides for 
pathogenic aggregation [3,24-27]. In amyloid peptide research, some short fragments (e.g., KLVFFAE, DFNKF, and NFGAIL) have been found to form amyloid fibrils similar to those formed by full-length proteins and polypeptides [21,24-26]. Gazit et al. have first demonstrated that the much shorter core sequence FF of the $\beta$-amyloid $(\mathrm{A} \beta)$ polypeptides can self-assemble into nanotubes with high stability and rigidity [28-30]. There are so far a number of derivatives and analogues based on this ultrashort structural motif that can form a wide variety of nanostructures and materials, many of which have been covered in detail by other reviews [31-33]. Recent work in the exploitation of the assemblies of FF and its derivatives as semiconductors reveals the great potential of the self-assembly of short peptides in advanced nanotechnological applications [34]. Overall, these inherent features of short peptide sequences have made their self-assembly highly attractive, in particular for the fabrication of novel materials tailored to specific applications. At the same time, rationally designed short peptides can act as ideal model systems for experimental and theoretical studies of complicated protein folding.

Following this introductory discussion, we outline the self-assembly of short peptides in Part II, in light of their composition and types and how these features impact on physical principles of folding. In part III, we focus on one type of self-assembling short peptides, i.e., surfactant-like peptides (SLPs), partly considering their unique properties and partly owing to our own intensive efforts to study them, and highlight recent research progress toward designing and tuning their self-assembly. We then introduce the application of SLPs in different technological fields in Part IV. At the end of the review, we give our perspective on the challenges and attractive future research directions associated with SLPs (Part V). 


\section{Outline of peptide self-assembly}

\subsection{Amino acids: the building blocks of peptides}

In living organisms, inherited traits are encoded in DNA sequences, which are made up of four different nucleotides arranged in a linear order. According to the central dogma proposed by Francis Crick [35], DNA sequences govern the synthesis of proteins that also have similar linear structures, and inherited traits are transferred into these functional molecules. In proteins, it is 20 different amino acids (the magic 20 called by Crick, although an additional 3 amino acids are known to occur with prokaryotes) that are strung together to form their primary structures, and similarly, their biological functions and related superstructures are encoded in the amino acid sequence, although post-translational modifications such as phosphorylation occur and are known to be important in signaling. Thus a particular protein predominantly differs from another by the precise amino acid composition and sequence. To a large extent, the structural diversity and functional versatility of proteins root in the 20 amino acids with completely different physicochemical and biological characteristics. For clarity and brevity, the three-letter codes and the single-letter codes are used to represent amino acids and peptide sequences, respectively, throughout the account.

All amino acids have the same $\mathrm{H}_{2} \mathrm{~N}-\mathrm{CH}-\mathrm{COOH}$ motif with only variations in the $\mathrm{R}$ group (side chain) attached to the $\mathrm{C} \alpha$ atom, with the exception of Pro that has a secondary amino group and whose side chain is directly linked to the backbone by the ring closure (Fig. 1a). Of them, Gly, with single hydrogen as its side chain, is the only achiral amino acid and the rest have the L-configuration. Gly is the simplest possible amino acid with no marked hydrophilic or hydrophobic property, and its hydrophobicity ( $\pi$ value) is defined as 0.0 in many published 
scales of amino acid hydrophobicity $[1,2,36,37]$. The $\pi$ values following the Fauchère and Pliška scale as the measure of hydrophobicity of the 20 amino acids are given in Fig. $1 \mathrm{~b}$. There are many ways to classify the 20 amino acids, and the most widely used approach is based on the polarity of the side chain. Accordingly, these natural amino acids can be roughly classified into three groups: (1) hydrophobic groups with apolar side chains, (2) those with uncharged polar side chains, and (3) those with charged side chains (Fig. 1a) [1,38]. The apolar side chains of the hydrophobic amino acids differ significantly in size and shape. For example, the aliphatic side chains of Ala, Val, and Leu have different carbon numbers; Leu and Ile have the same carbon number but different branching modes; Phe and Trp have bulky and rigid aromatic rings. Uncharged polar amino acids bear hydroxyl (Ser, Thr, and Tyr), amide (Asn and Gln), and thiol (Cys) groups in their side chains. Charged amino acids include the positively charged ones (Lys, Arg, and His) and the negatively charged ones (Asp and Glu). The three basic ones have completely different functional groups on their side chains, i.e., the $\varepsilon$-amino, guanidino and imidazole groups for Lys, Arg and His, respectively, thus leading to the distinct $\mathrm{pKa}$ values $(10.5,12.5$, and 6.0) for their side chains. In addition, Gly, Cys, and Pro are rather special because of their unique roles in driving protein folding, particularly in the process of globularization; Phe, Trp and Tyr carry aromatic side groups and are often called aromatic groups $[32,39,40]$. Due to the tremendous diversity of the 20 amino acids in their size, shape, and charge (Fig. 1a), their physiochemical properties (hydrophobicity and helix and $\beta$-sheet forming propensities) also differ significantly (Fig. 1b), thus providing a rich variety of intra- and inter-molecular interactions driving peptide self-assembly. 
These amino acids also show a great diversity in terms of their biochemical properties, as well exemplified by their many in vivo biological processes and functions. We here give a few simple examples. In addition to participating in enzymatic reactions as a nucleophile and the binding of heavy metals in metallothioneins, the thiol group of Cys plays an important role in protein architecture and stability by forming disulfide bonds. Nilsson et al. have demonstrated that cyclization of the ionic complementary peptide $\mathrm{Ac}-\mathrm{C}(\mathrm{FKFE})_{2} \mathrm{CG}-\mathrm{NH}_{2}\left(\mathrm{Ac}-\right.$ and $-\mathrm{NH}_{2}$ denote $\mathrm{N}$ - and C-terminal capping via acetylation and amidation, respectively) via an intramolecular disulfide bond imposes a conformational constraint and prevents the peptide from adopting a $\beta$-sheet structure and self-assembling; however, addition of reductants immediately triggers the peptide's self-assembly and hydrogelation [41]. The side chain phosphorylation and dephosphorylation (at the hydroxyl group) of Tyr are common yet important biological reactions in many organisms, catalyzed by protein kinases and phosphatases, respectively. Xu et al. have widely used these enzymatic reactions on Tyr to regulate the self-assembly of designed short peptides and the formation of gels that can inhibit bacterial and cancer cell growth [42-48]. Tyr is also the precursor to melanin pigments that are used by living organisms to adsorb UV radiation for protection and to produce colors [49]. Ulijn et al. have very recently designed a series of tyrosine-containing self-assembling tripeptides as tunable precursors for polymeric pigments [50]. Gln serves as a specific substrate for transglutaminase (TGase) that plays a crucial role in matrix cross-linking [51]. We have designed an amphiphilic short peptide $\mathrm{Ac}-\mathrm{I}_{3} \mathrm{QGK}-\mathrm{NH}_{2}$ that can undergo a distinct sol-gel transition to form rigid hydrogels upon addition of TGase, and the peptide can be used for rapid and effective hemostasis upon bleeding [52]. 
Overall, the diversity of amino acids in their physical, chemical, and biological properties endows peptide self-assembly with great potential for the fabrication of advanced materials with tailored superstructures and functions.

(a)

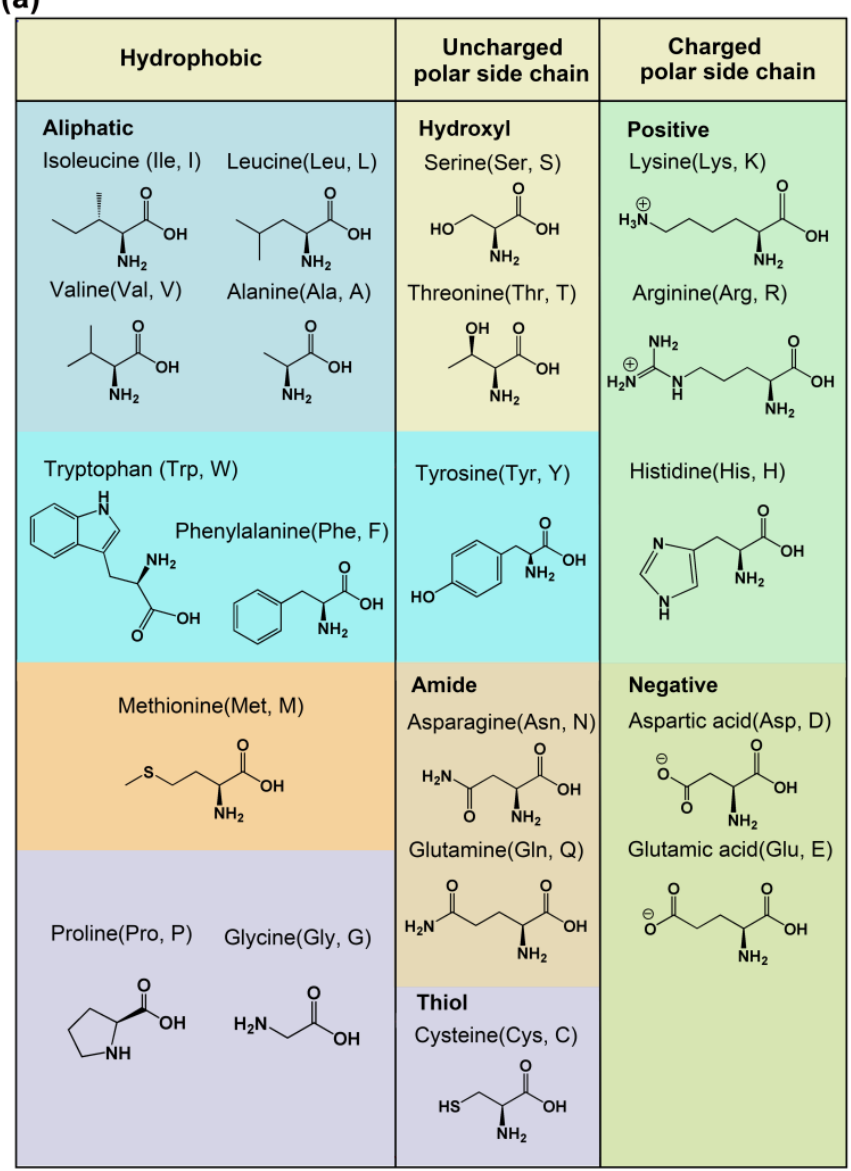

(b)

\begin{tabular}{|c|c|c|c|}
\hline Amino acid & Hydrophobicity & $\begin{array}{c}\alpha \text {-helix } \\
\text { propensity } \\
\text { (kcal / mol })\end{array}$ & $\begin{array}{c}\beta \text {-sheet } \\
\text { propensity } \\
\text { (kcal / mol })\end{array}$ \\
\hline Ala & 0.31 & 0.00 & 0.00 \\
Arg & -1.01 & 0.17 & -0.40 \\
Leu & 1.70 & 0.17 & -0.45 \\
Glu(0)/Glu(-) & $-/-0.64$ & $0.17 / 0.56$ & $-/-0.23$ \\
Met & 1.23 & 0.19 & -0.90 \\
Lys & -0.99 & 0.31 & -0.35 \\
Trp & 2.25 & 0.31 & -1.04 \\
Gln & -0.22 & 0.33 & -0.38 \\
Ser & -0.04 & 0.44 & -0.87 \\
Ile & 1.80 & 0.43 & -1.25 \\
Phe & 1.79 & 0.47 & -1.08 \\
Cys & 1.54 & 0.54 & -0.78 \\
Asp(0) / Asp(-) & $-/-0.77$ & $0.54 / 0.68$ & $-/ 0.85$ \\
Tyr & 0.96 & 0.56 & -1.63 \\
Asn & -0.60 & 0.61 & -0.52 \\
Thr & 0.26 & 0.61 & -1.36 \\
Val & 1.22 & 0.63 & -0.94 \\
Pro & $0.13 /-$ & $0.65 / 0.88$ & $-0.37 /-$ \\
His(0) / His(+) & 0 & 0.90 & 1.21 \\
Gly & & 3.47 & $>5$ \\
\hline
\end{tabular}

Fig. 1. (a) The 20 commonly occurring amino acids in eukaryotic cells and (b) their hydrophobicity (adapted from Ref. [36] with permission from Elsevier Ltd.) and $\alpha$-helix and $\beta$-sheet propensities (reproduced from Ref. [8] with permission from W. H. Freeman and Company). Note that (0), (-), and (+) in $\mathrm{b}$ denote the neutral, negatively charged, and positively charged form of ionizable side chains, respectively.

\subsection{Interactions involved in peptide self-assembly}

Similar to other molecular self-assembling systems, peptide self-assembly heavily relies on non-covalent interactions and, in some cases, relatively weak covalent bonds such as 
coordination bonds are also involved in [53,54]. Generally, the collective effect of numerous weak interactions provides a stable assembly process. These interactions tend to have their respective roles in regulating each step of the hierarchical self-assembly processes and final structures. Most importantly, these interactions work in a cooperative way, thus leading to complex, but coherent, self-assembly processes and enormous well-defined architectures.

\subsubsection{Various interactions}

Hydrogen bonding (H-bonding), hydrophobic interactions (including $\pi$ - $\pi$ stacking), electrostatic interactions, metal coordination and disulfide bridges are the main forces in protein folding and have been widely used in the design of peptide self-assembly.

The most distinctive feature in protein and peptide self-assembly is the involvement of an extensive H-bonding network, which originates from the peptide backbone or side chains. Backbone $\mathrm{CO} \cdots \mathrm{NH}$ bonds drive the formation of secondary structures such as $\alpha$-helices, $\beta$-sheets, and $\beta$-turns (Fig. 2a), which constitute the primary structural motifs for the hierarchical self-assembly processes of peptides and proteins. Fig. 1b lists $\alpha$-helix and $\beta$-sheet propensities of the 20 amino acids [8]. It is evident that these values vary for different amino acids, indicating a marked side-chain effect. As a typical example, Ile has stronger $\beta$-sheet propensity than Leu due to its $\beta$-branched side chain; however, such a branching mode destabilizes $\alpha$-helix formation, therefore resulting in the relatively low $\alpha$-helix propensity value associated with Ile. As another example, Pro and Gly are the most destabilizing group owing to their specific side chains [8]. Side-chain H-bonding can stabilize secondary structures, such as in the formation of polar zippers between $\beta$-strands proposed by Perutz et al. (Fig. 2a) [58,59]. By rational design of a series of SLPs $\left(A c-\mathrm{I}_{3} X \mathrm{GK}-\mathrm{NH}_{2}, X\right.$ denotes 
uncharged polar residues such as Gln, Ser, and Asn), we have demonstrated for the first time the formation of polar zippers between neighboring $\beta$-sheets rather than between $\beta$-strands within a sheet (Fig. 3) [60]. The polar zippers based on $X$ side chain H-bonding can intermesh $\beta$-sheets and overcome their inherent twisting, eventually leading to the formation of wide and flat ribbons. Such a super-secondary structural template could offer an agile route for the fabrication of distinctive nanostructures and nanomaterials beyond $\beta$-sheets [60]. Note that side chain-main chain H-bonding interactions may destabilize the helices [8,61].

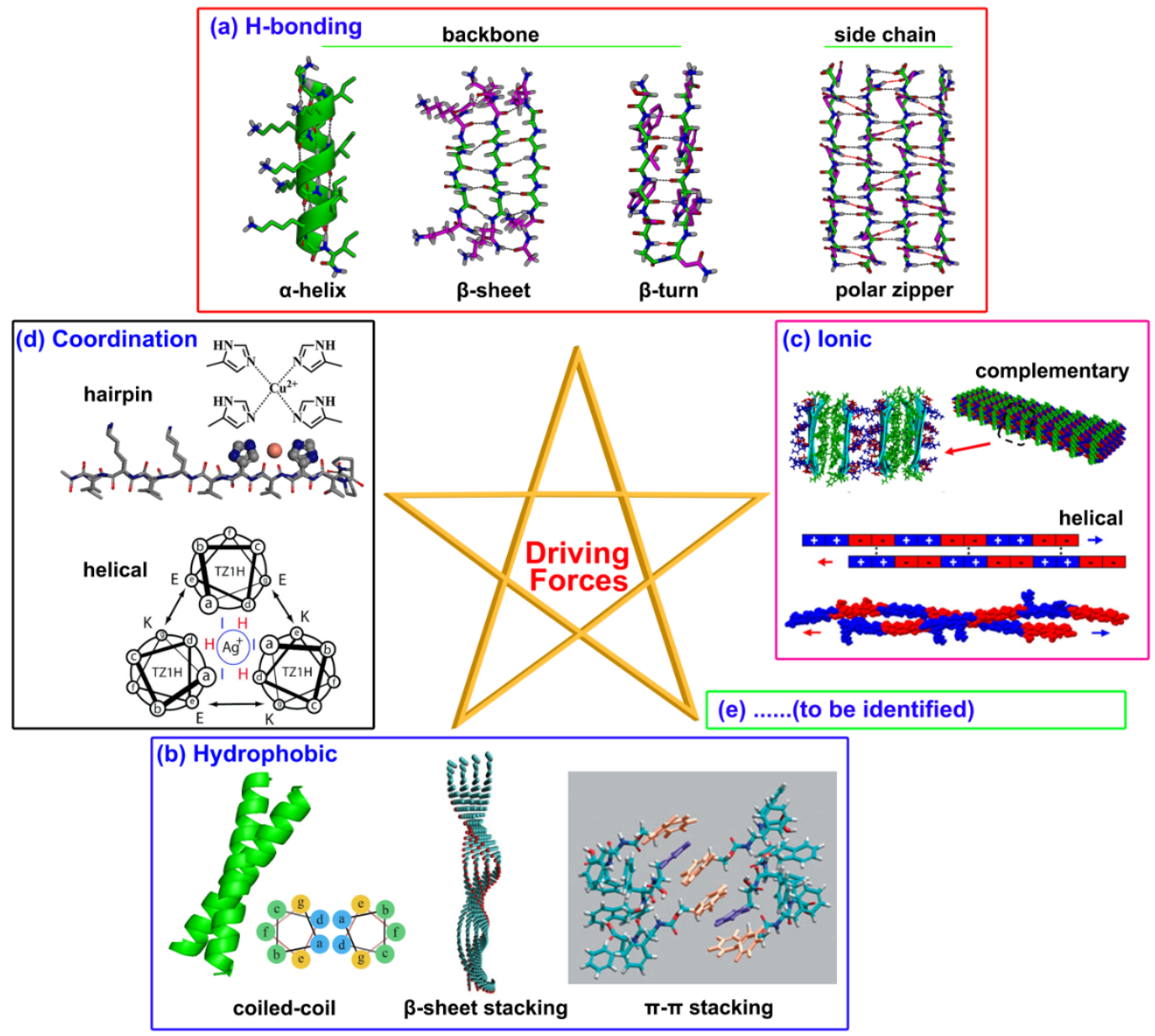

Fig. 2. The main driving forces involved in peptide self-assembly. (a) H-bonding: typical secondary structures ( $\alpha$-helix formed by an antibacterial peptide $\mathrm{G}(\mathrm{IIKK})_{3} \mathrm{I}-\mathrm{NH}_{2}$ [55], $\beta$-sheet by a bola-like SLP Ac- $\mathrm{KI}_{4} \mathrm{~K}-\mathrm{NH}_{2}$ [56], and $\beta$-turn by SWTWEGNKWTWK-NH ${ }_{2}$ [57]) and polar zipper by poly(L-glutamine) [59]. (b) Hydrophobic interactions in the formation of coiled-coils and the lateral stacking of $\beta$-sheets; $\pi-\pi$ 
stacking, reproduced from Ref. [62] with permission from Wiley-VCH Verlag $\mathrm{GmbH} \&$ Co. (c) Electrostatic interactions: ionic bridging in the self-assembly of ionic complementary peptides and helical peptides, adapted from Ref. [73] and [75], with permission of Elsevier Ltd. and National Academy of Science, respectively. (d) Coordination: heavy metal ion coordination specifically triggers the folding and self-assembly of hairpin peptides and helical peptides, reproduced from Ref. [78] and [79], with permission of Wiley-VCH Verlag GmbH \& Co. and American Chemical Society, respectively.

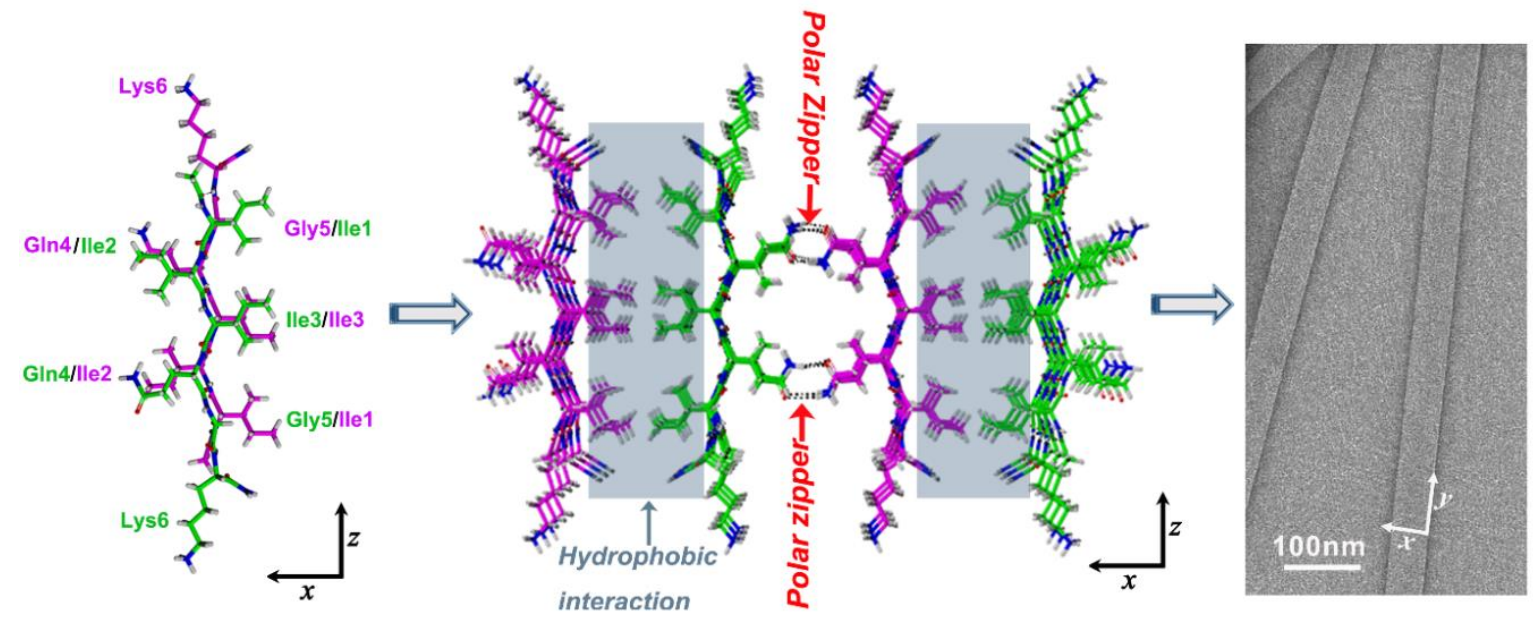

Fig. 3. Polar zippers between neighboring $\beta$-sheets leading to the formation of wide and rigid nanoribbons, adapted from Ref. [60] with permission Nature Publishing Group.

Apolar side chains are generally buried in the interior of a protein, away from contact with water, driven by the hydrophobic effect [2]. During peptide self-assembly in aqueous solution, intermolecular hydrophobic interactions act as the primary thermodynamic driving force, not only propelling peptide monomers to aggregate, but also promoting the secondary structures formed to undergo further assembly, such as in the formation of coiled-coils and in the lateral stacking of $\beta$-sheets (Fig. 2b). As opposed to H-bonding, hydrophobic interactions have been suggested to be non-directional by Whitesides et al [53]. However, $\pi$ - $\pi$ stacking as a specific hydrophobic interaction can provide directionality and remarkable level of order in the 
self-assembly of short amyloid peptides, their derivatives and analogues, due to the geometric restrictions of the stacking (Fig. 2b) $[25,28,31,32,62]$. Hydrophobic interactions mainly arise from the side chains of hydrophobic amino acids but some polar amino acids, such as Tyr and Thr, which have relatively higher hydrophobicity values (Fig. 1b), might also contribute appreciably to hydrophobic interactions $[63,64]$. Hydrophobic interactions can be readily tuned by varying the polarity of solvents $[65,66]$.

Although most intermolecular interactions are electrostatic in origin, we here limit the term electrostatic to the interactions between charged amino side chains, i.e., ionic interactions. Electrostatic interactions are either repulsive or attractive, depending on the signs of the charges. Charged amino acids are commonly distributed on the surfaces of peptide assemblies and thus dictate their hydration degree and stability in aqueous environments. Reduction of repulsions between amino acids bearing the same charges via $\mathrm{pH}$ adjustment and the addition of salts has been widely used to trigger self-assembly of hairpin peptides (e.g., Max1: VKVKVKVKV ${ }^{D}$ PPTKVKVKVKV-NH $2,{ }^{D} \mathrm{P}$ denotes Pro with the D-configuration) $[67,68]$ and peptide amphiphiles (PAs, e.g., $\mathrm{C}_{16} \mathrm{H}_{31} \mathrm{O}-\mathrm{CCCCGGGS}{ }^{\left(\mathrm{PO}_{4}\right)} \mathrm{RGD}, \quad \mathrm{S}^{\left(\mathrm{PO}_{4}\right)}$ denotes phosphoserine) [69,70]. Intermolecular electrostatic attractions between oppositely charged amino acids play an important role in the self-assembly of ionic self-complementary peptides (e.g., EAK16-II (AEAEAKAKAEAEAKAK) and KFE-8 (KFEFKFEF-NH $\left.{ }_{2}\right)$ [71-73] and helical peptides (e.g., hSAF system consisting of hSAF AAA-p (KIAALKAKIAALKAEIAALEAENAALEA) and hSAF AAA-p2 (KIAALKAKNAALKAEIAALEAEIAALEA) [74-77], as shown in Fig. 2c.

Approximately a third of naturally occurring proteins contain transition metal ions that can 
both help catalyze reactions and promote protein folding through metal coordination. Thus, metal coordination is also a major driving force for both peptide and protein self-assembly. Such an interaction often functions during the initial stages of peptide self-assembly, causing a conformational transition from random coils to certain secondary structures. Here metal ions typically require a specific geometry for successful coordination. For example, we have recently designed a hairpin peptide containing four His residues (Ac-VKVKVHVHV ${ }^{D}$ PPTHVHVKVKV-NH ${ }_{2}$ ) and demonstrated that only $\mathrm{Cu}^{2+}$ can specifically trigger its folding into facially amphiphilic $\beta$-hairpins by forming a tetragonal coordination geometry with four His residues (Fig. 2d), followed by their self-assembly into nanofibers and hydrogels [78]. For another example, addition of $\mathrm{Ag}^{+}$selectively induces the formation of a trimeric coiled-coil structural motif with sticky ends, by forming a trigonal planar geometry with three His residues (Fig. 2d), and the electrostatic attractions between sticky ends in turn promote longitudinal assembly into $\alpha$-helical coiled-coil fibrils [79].

\subsubsection{Cooperation}

In essence, it is unlikely that only one kind of force is responsible for peptide self-assembly, owing to the diversity of the constituent amino acids as well as the string of amide bonds that exists along the backbone. Even for ultrashort peptides, such as FF and Fmoc-FF, the contribution of H-bonding cannot be overlooked, in spite of the important role of $\pi$ - $\pi$ stacking in their self-assembly $[25,28,31,32,62]$. Although the above interactions have their respective roles in driving peptide self-assembly, they usually work in a cooperative manner and their interplay dictates the self-assembly process and the final nanostructures formed. One typical example is the self-assembly of two series of short SLPs, Ac- $\mathrm{L}_{\mathrm{m}} \mathrm{K}-\mathrm{NH}_{2}$ and $\mathrm{Ac}-\mathrm{I}_{\mathrm{m}} \mathrm{K}-\mathrm{NH}_{2}$ 
( $m=3-5)$ [80,81]. Ac- $\mathrm{L}_{3} \mathrm{~K}-\mathrm{NH}_{2}$ forms spherical stacks through a balance between the hydrophobic interactions between Leu side chains and the electrostatic repulsions between Lye side chains, and the peptide molecules adopt random coil conformations (Fig. 4a). In contrast, Ac- $\mathrm{I}_{3} \mathrm{~K}-\mathrm{NH}_{2}$ adopts a typical $\beta$-sheet structure and self-assembles into long nanofibers. Such differences are expected given that Ile has stronger $\beta$-sheet propensity than Leu. It is interesting that when the number of Leu residues is increased to five, the resultant Ac- $\mathrm{L}_{5} \mathrm{~K}-\mathrm{NH}_{2}$ also forms long nanofibers and more importantly, it also adopts a distinct $\beta$-sheet structure. It is evident from these results that increased hydrophobic interactions promote $\beta$-sheet structuring and the interplay between different interactions dictates the final self-assembled nanostructures. Furthermore, intermolecular $\beta$-sheet $\mathrm{H}$-bonding favors the longitudinal growth of peptide assemblies and this has also been confirmed by Hartgerink et $a l$, who demonstrated that upon selectively $\mathrm{N}$-methylating some key amino acid residues of $\mathrm{C}_{16} \mathrm{H}_{31} \mathrm{O}$-GGGGGGGERGDS, only spherical micelles form due to the lack of an extended $\beta$-sheet H-bonding network [82].

(a)

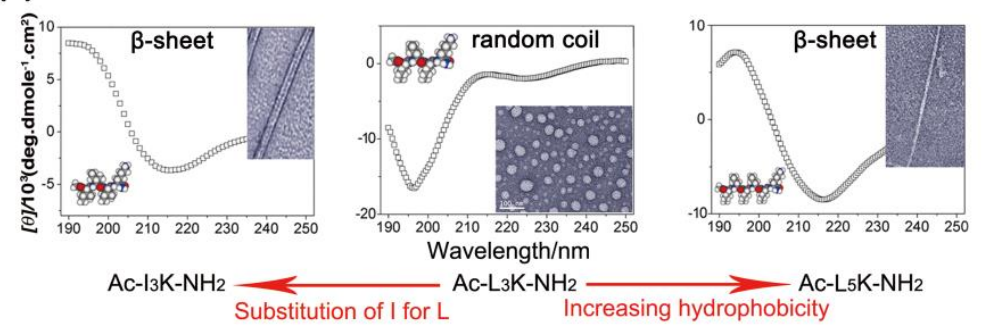

(b)

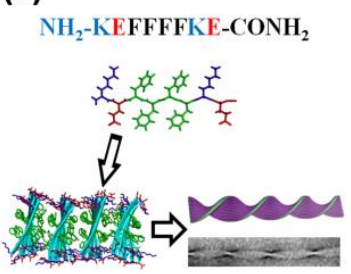

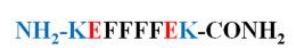

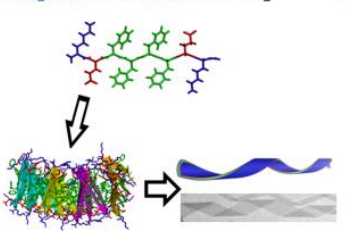

(c)

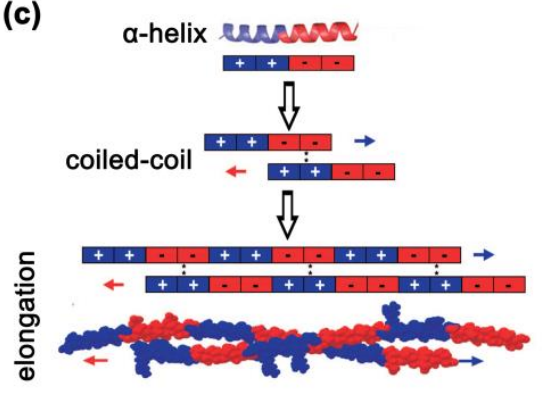

$\mathrm{NH}_{2}$-KFEFKFEF-CONH
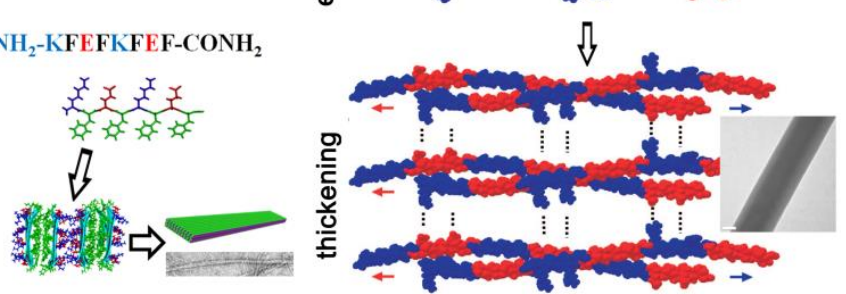

Fig. 4. The cooperative interplay of various weak interactions during peptide self-assembly. (a) The interplay of H-bonding and hydrophobic interactions, adapted from Ref. [80] with permission from 
Wiley-VCH Verlag GmbH \& Co. (b) The spatially cooperative effect of various non-covalent interactions, leading to different morphologies self-assembled from three ionic complementary peptides, adapted from Ref. [73] with permission of Elsevier Ltd. (c) The temporally cooperative effect of various non-covalent interactions, leading to a hierarchical self-assembly process for the helical peptides, adapted from Ref. [75], with permission of National Academy of Science.

Furthermore, the cooperative effect of various interactions is well-defined both spatially and temporally. We have designed three short ionic complementary peptides, KE-F8 (KEFFFFKE-NH $\left.{ }_{2}\right)$, EK-F8 (KEFFFFEK-NH $\mathrm{N}_{2}$ ), and KFE-8 (KFEFKFEF-NH $\left.{ }_{2}\right)$, with the same amino acid composition and length (Fig. 4b) [73]. Sequence variation makes the spatial distribution of amino acid residues different along the peptide backbone for the three peptides. As a result, the cooperation of the non-covalent forces involved (electrostatic, $\pi-\pi$ stacking, and H-bonding) is different spatially for the three peptides, eventually leading to different self-assembled nanostructures (twisted ribbons for KE-F8, helical ribbons/tubes for EK-F8 and flat ribbons for KFE-8), as shown in Fig. 4b. The temporally cooperative effect can be well exemplified in the assembly of $\alpha$-helical peptides [74-77]. As shown in Fig. 4c, intramolecular H-bonding first drives peptide molecules to adopt an $\alpha$-helix conformation, followed by the formation of dimeric coiled-coils with sticky ends primarily driven by the intermolecular hydrophobic interactions among hydrophobic residues at positions $a$ and $d$ (see Fig. $2 b$ for different positions of a helix). Then, the intermolecular electrostatic attractions between sticky ends (positions $e$ and $g$ ) cause longitudinal association into extended and thinner fibrils. Finally, the non-covalent interactions (ionic bridges and hydrophobic interactions) at positions $b, c$, and $f$ promote fibril thickening. 


\subsection{Typical self-assembling short peptides}

In this review, self-assembling short peptides refer to those with less than 30 residues. The pioneering work in this area dates back to the early 1990s. Through work on a yeast protein, zuotin, that could bind to the left-handed Z-DNA (zuo means left in Chinese), Zhang et al. serendipitously discovered that a repetitive sequence EAK16-II from the protein could self-assemble into stable membranes and ordered nanofibers [71,72]. In the meantime, Ghadiri et al. designed cyclic peptides with an even number of alternating D- and L-forms of amino acids, such as $c y c l o\left(-{ }^{D} \mathrm{AE}^{D} \mathrm{AQ}^{D} \mathrm{AE}^{D} \mathrm{AQ}-\right)$, that could adopt a flat-ring conformation and stack to furnish a contiguous H-bonded hollow tubular structure [83]. Since then, the combination of serendipity and intelligent molecular design has led a wide variety of self-assembling short peptides. There are of course extensive variations that are based on the two parent peptide sequences [72,84].

The self-assembling short peptides reported so far can be roughly classified into the following groups: ionic complementary peptides (e.g., EAK16-II) [71], cyclic peptides (e.g., cyclo(- $\left.\left.{ }^{D} \mathrm{AE}^{D} \mathrm{AQ}^{D} \mathrm{AE}^{D} \mathrm{AQ}-\right)\right)$ [83], PAs (e.g., $\left.\mathrm{C}_{16} \mathrm{H}_{31} \mathrm{O}-\mathrm{CCCCGGGS}^{\left(\mathrm{PO}_{4}\right)} \mathrm{RGD}\right)$ [69], SLPs (e.g. Ac- $\left.\mathrm{A}_{6} \mathrm{D}\right)$ [85], hairpin peptides (e.g., Max1) [67], amyloid peptide fragments and derivatives (e.g., FF and Fmoc-FF) [28,62], multidomain peptides (MDPs, e.g., Ac- $\mathrm{K}_{2}(\mathrm{QL})_{6} \mathrm{~K}_{2}-\mathrm{NH}_{2}$ ) [86], and helical peptides (e.g., hSAF peptides) [74]. Note that these presented peptides correspond to the first or bets-known report on each group of self-assembling peptides. Apart from helical peptides, the rest tend to adopt $\beta$-sheet structures upon self-assembly. Most of them are de novo designed but their molecular design has greatly benefited from the understanding of protein sequence-structure relationships. Such a classification scheme is not exhaustive but it 
does provide a taste of the most significant advances in the area.

Of the different peptide groups, PAs and SLPs are linear and amphiphilic [87-89]. They are structurally akin to conventional surfactants and have well-defined hydrophobic and hydrophilic moieties. Such a structural hallmark makes it relatively easy to design their molecular sequences for targeted superstructures and applications. SLPs are exclusively composed of amino acid residues, as opposed to PAs which are usually composed of a long alkyl chain covalently attached to a peptide sequence $[69,70]$. Furthermore, the number of their residues is commonly less than 10, in sharp contrast to $\alpha$-helical self-assembling peptides that contain dozens of residues [74-77,79]. Importantly, SLPs generally have higher solubility in aqueous solution, thus favoring their applications in biomedicines health care and cosmetics. The subsequent sections of the review will focus on SLPs, mostly based on examples from our own research. Stupp research group has contributed significantly to the design, self-assembly, and applications of PAs [69,70,90], and major progresses in this area have been already covered in their recent reviews [91-93].

\section{Design rules of SLPs and their controllable self-assembly}

The initial design of SLPs was curiosity-driven. In 1992 at the "Origin of Life" Gordon Conference in New Hampshire, Shuguang Zhang from Massachusetts Institute of Technology asked two seemingly simple innocuous questions [94]. (1) What are the simplest amphiphilic biomolecules that could self-assemble in the prebiotic aqueous environment to form a primitive enclosure in which other biological molecules could accumulate and evolve? (2) Could such a structure be made and self-assembled from the simplest amino acids? The second question was raised because the syntheses of phospholipids, nucleic acids and proteins in the prebiotic 
environment appeared to be rather unlikely, while peptide bond formation under high temperature and pressure conditions seems relatively straightforward. With those questions in mind, the first SLP, Ac- $\mathrm{A}_{6} \mathrm{D}$, was designed by Zhang and coworkers in 2002 [85]. It consists of six consecutive hydrophobic residues and a negatively charged and thus carries two negative charges at the C-terminus (one from the side chain carboxyl group and the other from the C-terminal carboxyl group). This peptide and other anionic SLPs, such as $A c-V_{6} D, A c-V_{6} D_{2}$, and $A c-G_{6} D_{2}$, undergo self-assembly in neutral aqueous solutions to form nanotubes and nanovesicles, and those nanostructures were suggested to act as the primitive enclosure for the primordial ribozymes and rudimentary peptide enzymes $[85,95]$.

Since 2002, a number of SLPs have been designed and widely explored. The most extensively investigated SLPs are those with a hydrophobic tail that consists of several of the same hydrophobic residues and a hydrophilic head group comprised of one or two same charged residues (Fig. 5a), such as anionic $A c-V_{6} D$ and cationic $A c-A_{6} K-N_{2}$ and $A_{6} K$ [85,96-99]. When the hydrophobic residues are different, gradual increases or decreases in their side chain size or hydrophobicity along the backbone gives rise to cone-shaped SLPs, such as Ac-GAVILRR-NH ${ }_{2}$, Ac-AAVVLLLWEE, and Ac-LIVAGD (Fig. 5a) [100-103]. Several bola-like SLPs such as $\mathrm{Ac}-\mathrm{KI}_{4} \mathrm{~K}-\mathrm{NH}_{2}, \mathrm{Ac}-\mathrm{HI}_{4} \mathrm{H}-\mathrm{NH}_{2}$, and $\mathrm{EFL}_{4} \mathrm{FE}$ have been recently designed, where two same terminal charged residues are linked by a hydrophobic amino acid core (Fig. 5a) [56,66,104-107].

Similar to conventional surfactants, many SLPs have a well-defined critical aggregation concentration (CAC) $[80,87,88,99,100,101,108-113]$. In addition to hydrophobicity, $\beta$-sheet H-bonding also plays an important role in dictating their CACs. For example, despite their 
similar hydrophobicity, Ac- $\mathrm{I}_{3} \mathrm{~K}-\mathrm{NH}_{2}$ has a markedly lower $\mathrm{CAC}$ value in water than Ac- $\mathrm{L}_{3} \mathrm{~K}-\mathrm{NH}_{2}$, due to the lack of $\beta$-sheet structuring in the latter [80]. However, the CACs of Ac- $\mathrm{I}_{5} \mathrm{~K}-\mathrm{NH}_{2}$ and $\mathrm{Ac}-\mathrm{L}_{5} \mathrm{~K}-\mathrm{NH}_{2}$ are nearly identical, because they both form $\beta$-sheet secondary structures. Above their CACs, SLPs can readily undergo self-assembly in aqueous solutions and a wide range of ordered nanostructures and materials, such as micelles, vesicles, nanofibers, nanoribbons, nanotubes, and hydrogels, have been so far reported from their self-assembly. Because of their short length, well-defined hydrophobic and hydrophilic regions, molecular amphiphilicity, and excellent water solubility, the self-assembly and applications of SLPs can be readily tuned through appropriate molecular design and varying solution conditions, as illustrated below.

\subsection{Molecular design rules}

As indicated above, the great diversity of amino acids in their structures, physiochemical properties, and biological functions makes it feasible to create a huge number of peptide building blocks with distinctive self-assembly features and functions. In the following, we outline several simple and effective rules for the rational design of SLPs: amino acid substitution, sequence variation, length variation, chirality, and amino acid incorporation.

\subsubsection{Amino acid substitution}

Amino acid substitution provides a simple and straightforward way to design SLPs. Following this approach, a specific non-covalent interaction is modified but other interactions remain almost constant. The self-assembly of $\mathrm{Ac}-\mathrm{I}_{3} \mathrm{~K}-\mathrm{NH}_{2}$ and its substitutions is a typical example, as shown above $[80,81]$. Our MD simulations revealed that bola-like SLPs tend to adopt extended conformations due to their molecular symmetry, which in turn favors the 
lateral stacking of $\beta$-sheets and eventually the formation of ribbons and nanotubes $[56,66]$. For another example, we have recently designed two series of bola-form hexapeptides, Set 1 consisted of Ac- $\mathrm{KI}_{4} \mathrm{~K}-\mathrm{NH}_{2}, \mathrm{Ac}-\mathrm{KI}_{3} \mathrm{NleK}-\mathrm{NH}_{2}, \mathrm{Ac}-\mathrm{KI}_{3} \mathrm{LK}-\mathrm{NH}_{2}$, and $\mathrm{Ac}-\mathrm{KI}_{3} \mathrm{TleK}-\mathrm{NH}_{2}$, in which substitution for Ile in the C-terminal alters its side chain branching but the hydrophobicity is retained; Set 2 consisted of $A c-\mathrm{KI}_{3} \mathrm{VK}-\mathrm{NH}_{2}, \quad \mathrm{Ac}-\mathrm{KI}_{2} \mathrm{~V}_{2} \mathrm{~K}-\mathrm{NH}_{2}$, Ac- $\mathrm{KIV}_{3} \mathrm{~K}-\mathrm{NH}_{2}$, and $\mathrm{Ac}-\mathrm{KV}_{4} \mathrm{~K}-\mathrm{NH}_{2}$, in which the substitution of Val for Ile leads to the decrease of hydrophobicity but the side chain $\beta$-branching is retained [114]. These peptides were found to form monolayer nanotubes and their diameter can be finely tuned from more than $100 \mathrm{~nm}$ to several nanometers by changing the branching mode and hydrophobicity of the hydrophobic core residues (Fig. 5b). In another study on this kind of bola-like SLPs, hydrophilic amino acid substitutions at the two termini of $\mathrm{Ac}-\mathrm{KI}_{4} \mathrm{~K}-\mathrm{NH}_{2}$ lead to different packing modes of $\beta$-sheets and their resultant nanostructures: flat multilayer nanoribbons for Ac- $-\mathrm{HI}_{4} \mathrm{H}-\mathrm{NH}_{2}$ and twisted bilayer nanoribbons for $\mathrm{Ac}-\mathrm{RI}_{4} \mathrm{R}-\mathrm{NH}_{2}$ [105].

\subsubsection{Sequence variation}

Another effective and direct method in the design of SLPs is sequence variation, in which the amino acid composition remains unchanged. The delicate balance of different cooperative non-covalent interactions is usually changed as a result. A typical example is the self-assembly of Ac- $\mathrm{KI}_{4} \mathrm{~K}-\mathrm{NH}_{2}$ and $\mathrm{Ac}-\mathrm{I}_{4} \mathrm{~K}_{2}-\mathrm{NH}_{2}$ [104]. The two SLPs were found to adopt typical $\beta$-sheet secondary conformations and self-assemble into distinct morphologies, wider nanotubes for $\mathrm{Ac}-\mathrm{KI}_{4} \mathrm{~K}-\mathrm{NH}_{2}$, while thinner nanofibers were observed with $\mathrm{Ac}-\mathrm{I}_{4} \mathrm{~K}_{2}-\mathrm{NH}_{2}$ (Fig. 5b). In the former case, the hydrophobic adhesion between the Ile side chains of neighboring $\beta$-sheets is unaffected by the electrostatic repulsion between the Lys side chains, due to the 
symmetric distribution of the two charged residues along the backbone [56,104]. This causes significant untwisting and lateral stacking of $\mathrm{Ac}-\mathrm{KI}_{4} \mathrm{~K}-\mathrm{NH}_{2} \beta$-sheets, followed by the formation of helical ribbons with larger widths that finally develop into wide nanotubes. In the latter case, the electrostatic repulsion among the Lys side chains destabilizes the hydrophobic contacts of neighboring $\beta$-sheets, resulting in the limited association of $\beta$-sheets with inherently twisting and eventually the formation of nanofibers. In general, sequence variation has been widely used to tune the balance of various non-covalent interactions and to construct distinctive morphologies, such as in the design of ionic complementary peptides (Fig. 4b) [73], PAs [115], and amyloid-like peptides [50].

\subsubsection{Length variation}

Just like conventional surfactants, the self-assembly behavior of SLPs can be easily regulated by varying the hydrophobic tail length. Thus, many SLPs with the same hydrophilic head but different hydrophobic lengths have been designed $[80,95,97,99]$. The self-assembly of Ac- $\mathrm{A}_{\mathrm{m}} \mathrm{K}-\mathrm{NH}_{2}(m=3,6,9)$ and $\mathrm{Ac}-\mathrm{I}_{\mathrm{m}} \mathrm{K}-\mathrm{NH}_{2}(m=4-6)$ is closely related to their hydrophobic tail length, given that they all adopt $\beta$-sheet secondary structures $[80,97]$. With an increase in the hydrophobic tail length, the self-assembled architectures show a reduction in dimension, from stacked bilayers for $\mathrm{Ac}-\mathrm{A}_{3} \mathrm{~K}-\mathrm{NH}_{2}$, long cylindrical nanofibers for $\mathrm{Ac}-\mathrm{A}_{6} \mathrm{~K}-\mathrm{NH}_{2}$, to thinner nanorods and micelles for $\mathrm{Ac}-\mathrm{A}_{9} \mathrm{~K}-\mathrm{NH}_{2}$ (Fig. 5b) [97]. The dimensional reduction can be interpreted using the molecular packing theory developed to describe structural transitions of conventional surfactants $[97,116]$.

\subsubsection{Chirality}

For peptides and proteins, the chirality of constituent amino acids plays a pivotal role in 
controlling the handedness of their folding and supramolecular organization. In a recent study, we investigated how amino acid chirality affects the handedness of the nanostructures self-assembled from SLPs, through designing three pairs of enantiomeric short amphiphilic peptides: Ac- ${ }^{L} \mathrm{I}_{3}{ }^{L} \mathrm{~K}-\mathrm{NH}_{2}$ and $\mathrm{Ac}_{-}{ }^{D} \mathrm{I}_{3}{ }^{D} \mathrm{~K}-\mathrm{NH}_{2}, \quad A c-{ }^{L} \mathrm{I}_{3}{ }^{D} \mathrm{~K}-\mathrm{NH}_{2}$ and $\mathrm{Ac}-{ }^{D} \mathrm{I}_{3}{ }^{L} \mathrm{~K}-\mathrm{CONH}_{2}$, and Ac- ${ }^{L a} \mathrm{I}_{3}{ }^{L} \mathrm{~K}-\mathrm{NH}_{2}$ and $\mathrm{Ac}-{ }_{-}^{D a} \mathrm{I}_{3}{ }^{D} \mathrm{~K}-\mathrm{NH}_{2}$ (Ile has two chiral centers, and ${ }^{L} \mathrm{I},{ }^{D} \mathrm{I},{ }^{L a} \mathrm{I}$, and ${ }^{D a} \mathrm{I}$ denote L-, D-, L-allo-, and D-allo-isoleucine, respectively) [117]. The results indicate that the handedness of a nanofiber's twisting is determined by the chirality of the charged Lys residue at the C-terminus (Fig. 5b). In contrast, their characteristic CD signals are dictated by the chirality of the three hydrophobic Ile residues. Molecular dynamic (MD) simulations described the evolution of handedness from molecular chirality at the atomic scale to supramolecular handedness at large scales of microns. Varying the chirality of constituent amino acids might be a facile strategy to regulate the handedness of peptide-based aggregates [117-124].

\subsubsection{Amino acid incorporation}

By incorporating certain amino acids or sequence into peptide building blocks, the resultant self-assembled nanostructures can be endowed with specific functions. However, such a strategy requires high robustness and stability of the building blocks and their self-assembly. Fortunately, due to the high hydrophobicity and strong propensity for $\beta$-sheet structuring of Ile, the designed Ac- $\mathrm{I}_{3} \mathrm{~K}-\mathrm{NH}_{2}$ has a strong self-assembling ability and the nanofibers formed show high stability [108]. Based on this short peptide, we have designed $\mathrm{Ac}-\mathrm{I}_{3} \mathrm{CGK}-\mathrm{NH}_{2}$ and Ac- $\mathrm{I}_{3} \mathrm{QGK}-\mathrm{NH}_{2}$, by inserting a functional Cys or Gln residue at the hydrophobic/hydrophilic interface $[52,125]$. Such incorporation was demonstrated to not only have little influence on 
their self-assembling ability, but also endow the self-assembled nanostructures with specific functions. For example, the $\mathrm{Ac}-\mathrm{I}_{3} \mathrm{QGK}-\mathrm{NH}_{2}$ solution undergoes a rapid sol-gel transition upon addition of TGase and has been successfully used for effective hemostasis [52]. In another study, a short SLP, Ac- $\mathrm{I}_{3} \mathrm{SLKG}-\mathrm{NH}_{2}$, was designed by engineering a protease cleavage site motif into the sequence, and its self-assembled fibrous hydrogels show obvious degradation in response to MMP-2 [126].

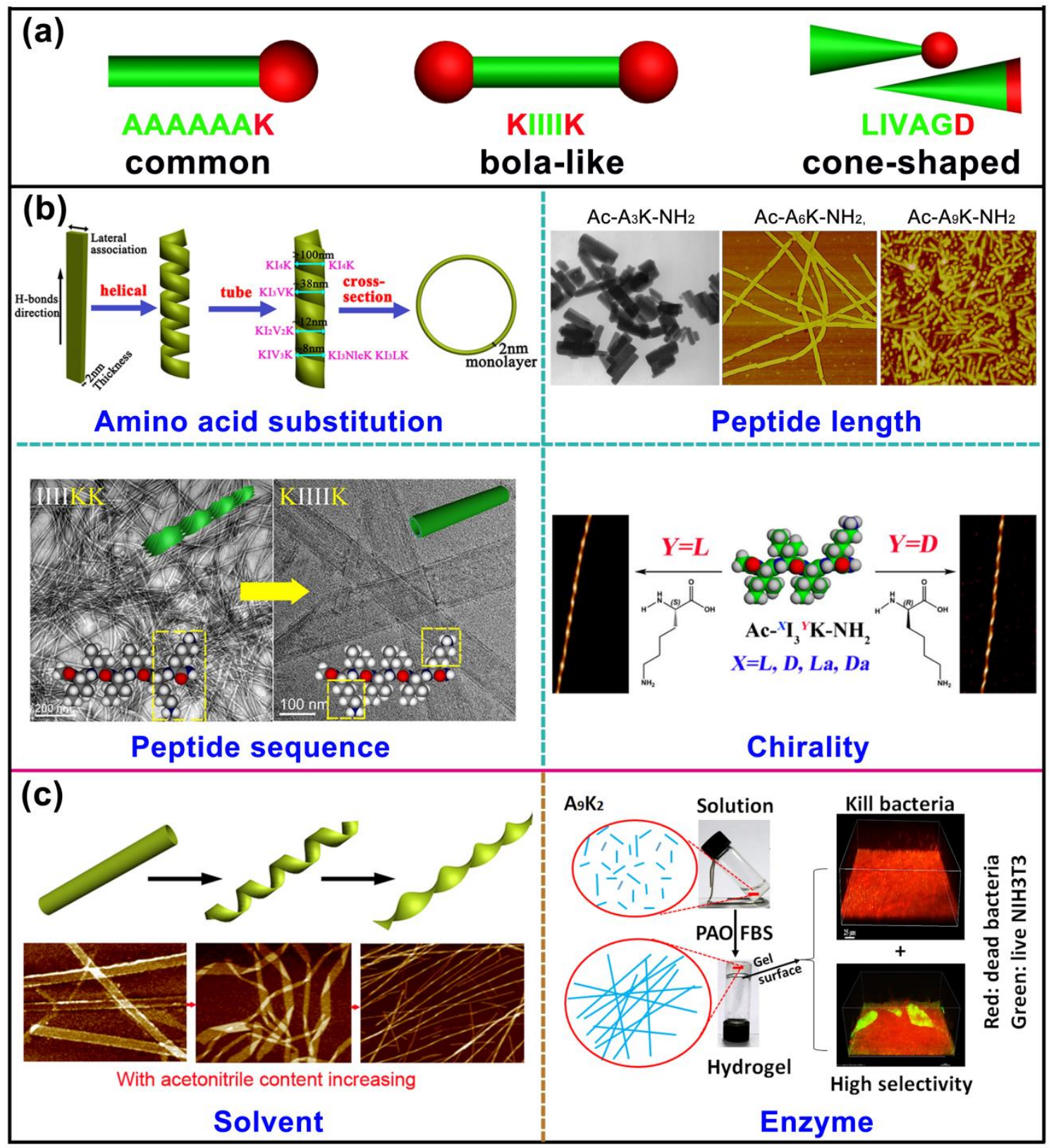

Fig. 5. Representative approaches that affect the self-assembly processes of SLPs. (a) Main types of SLPs: 
conventional, bola-like, and cone-shaped. (b) Molecular design strategies: amino acid substitution, sequence variation, length increase, and chirality, reproduced from Ref. [114], [104], [97], and [117], respectively, with permission of Wiley-VCH Verlag GmbH \& Co. and American Chemical Society. (c) External factors used for controlling the self-assembly of SLPs: solvents and enzymes, adapted and reproduced from Ref. [66] and [132], respectively, with permission of American Chemical Society. Note that cationic SLPs are capped at both termini and anionic ones only capped at N-terminus, and for brevity, Ac- and $-\mathrm{NH}_{2}$ are omitted in some images.

\subsection{External factors}

Weak non-covalent interactions can be susceptible to environmental interferences due to changes in $\mathrm{pH}$, ionic strength, solvent, temperature, and light conditions. Furthermore, some polar amino acids generally act as active sites for metal coordination and enzymatic reactions. These characteristic features make some peptide self-assembly systems sharply responsive to external stimuli. Therefore, external factors have been extensively used to control peptide self-assembly, in addition to molecular design, which have largely covered in several excellent reviews $[32,33,39,43,47,48,91,127]$. For brevity, we here exemplify this strategy only with the effects of organic solvent and enzymes on the self-assembly of SLPs.

\subsubsection{Solvents}

Addition of an organic solvent into peptide solutions can be used to tune the solution polarity, which in turn mainly affects the hydrophobic interaction involved $[65,66]$. As indicated above, the formation of wider $\mathrm{Ac}-\mathrm{KI}_{4} \mathrm{~K}-\mathrm{NH}_{2}$ nanotubes is primarily driven by the hydrophobic interaction between the Ile side chains of neighboring $\beta$-sheets and it is much less affected by the electrostatic repulsion between the Lys side chains [104]. Therefore, we 
have selected the bola-like SLP as an ideal model to explore solvent effects on the hydrophobic interaction and the resultant aggregate morphologies [66]. As expected, introduction of acetonitrile into water can significantly decrease the hydrophobic interactions between Ile side chains and induce structural transitions from nanotubes to twisted/helical ribbons and then to thin nanofibers (Fig. 5c). MD simulations indicate that acetonitrile tends to enter into the hydrophobic domains and leads to the separation of neighboring $\beta$-sheets, effectively weakening the hydrophobic interactions.

\subsubsection{Enzymes}

Enzymes are essential to life, and in the past two decades enzymes have been widely used as biological stimuli to trigger peptide self-assembly and dis-assembly. The groups of Ulijn , $\mathrm{Xu}$, and others have made noteworthy advances in this aspect, not only proposing the concept of enzyme-instructed self-assembly (EISA) but also developing the surface-confined EISA method to produce localized self-assembling hydrogels [42-48,63,128-130, Angew. Chem. Int. Ed. 2015, 54, 10198-10201, Langmuir 2017, 33, 8267-8276]. Similar to Ac-A $\mathrm{A}_{9}-\mathrm{NH}_{2}$, Ac- $\mathrm{A}_{9} \mathrm{~K}_{2}-\mathrm{NH}_{2}$ also self-assembles into micelles and short nanorods and can kill bacteria via a membrane lysis mechanism [131]. Addition of fetal bovine serum (FBS) and plasma amine oxidase (PAO) makes the peptide solution undergo a sol-gel transition, accompanied by the formation of long entangled nanofibers [132]. Furthermore, bacterial growth both in the solution above the resulting $\mathrm{Ac}-\mathrm{A}_{9} \mathrm{~K}_{2}-\mathrm{NH}_{2}$ hydrogel and at the gel surface can be strongly inhibited. Under co-culturing conditions, the peptide hydrogel displays excellent selectivity by favoring the adherence and spread of mammalian cells, whilst killing pathogenic bacteria. It is therefore capable of reducing bacterial contamination (Fig. 5c). 


\section{Applications}

As a result of their unique physical and structural properties and ease of molecular design and synthesis, SLPs have shown potential for applications in a wide range of fields, particularly in biotechnology and biomedicines, such as cell culture, antibacterial and anticancer materials, drug and gene delivery and controlled release, hemostasis, biomimetic mineralization, nanofabrication, and membrane protein stabilization.

\subsection{Hydrogel scaffold for cell culture}

Many peptides can self-assemble into long and entangled fibers in aqueous solution and then form fibrous hydrogels. Because of their inherent biocompatibility and biodegradability, self-assembling peptide hydrogels have been most frequently used as 2D and 3D bioinspired scaffolds for cell culture, tissue engineering, and regenerative medicine $[31,54,72,77,88-93,133-140]$.

Hauser et al have demonstrated that the hydrogel formation of cone-shaped SLPs is dependent on the length of the hydrophobic tail and the polarity of the head group [103]. The resulting hydrogels display tunable, high mechanical strengths and are heat resistance up to 90 ${ }^{\circ} \mathrm{C}$. The Ac-LIVAGD gels can entrap up to $99.9 \%$ water at a concentration of $1 \mathrm{mg} / \mathrm{mL}$ and thus resemble networks of collagen fibers found in the extracellular matrix (ECM). More importantly, these gels are biocompatible and a variety of mammalian primary cells such as human mesenchymal stem cells, human primary renal tubular cells, rabbit retinal pigment epithelial cells, and porcine nucleus pulposus cells have been successfully cultured on the hydrogels. Given the easy and cost-effective synthesis of these ultrashort SLPs, the hydrogel materials would be attractive in a wide range of biomedical applications. Recently, some of 
them with adequate mechanical strength and stiffness have been exploited as inks for printing 3D patterned scaffolds, which support the 3D culture of human stem cells and differentiation of primary cells into organotypic structures (Fig. 6a) [141].

Through suitable molecular design or using enzymatic stimuli, SLP hydrogels can be endowed with specific functions. For examples, the $\mathrm{Ac}-\mathrm{I}_{3} \mathrm{SLKG}-\mathrm{NH}_{2}$ hydrogels display a specific degradation behavior in the presence of MMP-2, due to the incorporation of an MMP-2 cleavage site into the sequence through molecular design [126]. As another example, enzymatic Ac- $\mathrm{A}_{9} \mathrm{~K}_{2}-\mathrm{NH}_{2}$ hydrogels show excellent antibacterial ability against both Gram-negative and Gram-positive bacteria, while possessing low cytotoxicity against mammalian cells (Fig. 5c) [132].

\subsection{Antibacterial and anticancer activity}

Cationic SLPs with lysine and arginine residues as their hydrophilic head have shown broad-spectrum antibacterial ability, with a low probability of inducing drug resistance and the likely transfer across the blood-brain barrier [131,142-144]. In general, SLPs kill via membrane permeabilization or lysis (Fig. 6b). The antibacterial ability of SLPs is related to their hydrophobicity, charge, amphiphilicity, and self-assembled size and morphology. For example, in contrast to $\mathrm{Ac}-\mathrm{A}_{3} \mathrm{~K}-\mathrm{NH}_{2}$ and $\mathrm{Ac}-\mathrm{A}_{6} \mathrm{~K}-\mathrm{NH}_{2}, \mathrm{Ac}-\mathrm{A}_{9} \mathrm{~K}-\mathrm{NH}_{2}$ forms much smaller aggregates (micelles and nanorods) and show potent antibacterial activity, with an increase in its hydrophobic tail length [142]. Ac- $\mathrm{A}_{9} \mathrm{~K}_{2}-\mathrm{NH}_{2}$ and $\mathrm{Ac}-\mathrm{A}_{12} \mathrm{~K}-\mathrm{NH}_{2}$ also form micelles and nanorods but show compromised antibacterial activities relative to $\mathrm{Ac}-\mathrm{A}_{9} \mathrm{~K}-\mathrm{NH}_{2}$, indicating the importance of molecular amphiphilicity, i.e., the balance of hydrophobicity and charge dictates the antibacterial effect [132]. Evidently, the physiochemical properties of SLPs can be 
fine-tuned through molecular design. The design of such antibacterial SLPs could benefit from recent progress in advanced computer-assisted drug design [145,146].

As a result of the presence of phosphatidylserine (PS), O-glycosylated mucins, sialylated gangliosides, and heparin sulfate, the outer membrane of some cancer cells carries net negative charges similar to bacterial cells. As a consequence, $\mathrm{Ac}-\mathrm{A}_{9} \mathrm{~K}-\mathrm{NH}_{2}$ has been demonstrated to markedly inhibit the growth of cancerous HeLa cells while be benign to Cos 7 cells, NIH3T3 cells and human red blood cells [132,147]. In addition to inducing membrane disruption, the SLP can enter into the cytoplasm and interact with mitochondria and the nucleus of HeLa cells, thereby resulting in cell apoptosis [147].

\subsection{Drug delivery}

Drug delivery with lipid or surfactant vesicles and micelles as vectors has been extensively explored since the 1970s. Due to the similarity to lipids and surfactants, SLPs have been exploited for drug and gene delivery over the past few years [126,148-150]. Fatouros et al. have prepared nanovesicles with different sizes and morphologies, through the self-assembly of Ac- $\mathrm{A}_{6} \mathrm{~K}-\mathrm{NH}_{2}, \mathrm{KA}_{6}-\mathrm{NH}_{2}, \mathrm{Ac}-\mathrm{A}_{6} \mathrm{D}$ and $\mathrm{DA}_{6}$ in PBS with high ionic strength, and used them to encapsulate hydrophilic and hydrophobic model drugs [148]. Of them, Ac- $\mathrm{A}_{6} \mathrm{D}$ may be most suitable for drug delivery, due to the sustained release of entrapped compounds from Ac- $\mathrm{A}_{6} \mathrm{D}$ nanovesicles and their negative charge. In another study, $\mathrm{Ac}-\mathrm{A}_{6} \mathrm{D}$ was demonstrated to significantly enhance the transport of FITC-dextran across the epithelial monolayer [149]. Therefore, Ac- $\mathrm{A}_{6} \mathrm{D}$ may be preferable as a permeation enhancer for oral drug administration, given its good biocompatibility [149]. Wang et al. have demonstrated that two model drugs, i.e., hydrophilic methyl orange and hydrophobic oil red, can be efficiently encapsulated by the 
Ac- $\mathrm{I}_{3} \mathrm{~K}-\mathrm{NH}_{2}$ assemblies and the release of encapsulated compounds can be regulated by $\mathrm{pH}$ adjustment [150]. It is evident that when SLPs are used in drug delivery, the loading capability and the release profiles can be controlled by molecular design and external factors.

Peptide hydrogels have also been also used for drug delivery. As indicated above, the Ac- $\mathrm{I}_{3} \mathrm{SLKG}-\mathrm{NH}_{2}$ hydrogels can be degraded by the addition of MMP-2. When an anticancer peptide $\mathrm{G}(\mathrm{IIKK})_{3} \mathrm{I}-\mathrm{NH}_{2}$ was entrapped into the hydrogels, its release occurred in a "cell-dependent" manner in the presence of HeLa cells that over-express MMP-2, therefore leading to a marked inhibitory effect on their growth on the gels (Fig. 6c) [126]. In order to achieve controlled drug delivery and higher efficacy, Yang, Xu and coworkers have designed a series of drug-peptide amphiphilies by conjugating hydrophobic anticancer drugs (e.g., taxol and 10-hydroxycamptothecine) to the N-terminal or the side chain of amphiphilic peptides (e.g., FFERGD and $\left.{ }^{D} \mathrm{~F}^{D} \mathrm{~F}^{D} \mathrm{Y}\right)$. (JACS 2013, 135, 9907-9914; JACS 2017, 139, 2876-2879; Nanoscale 2017, 9, 11987-11993; Adv. Healthcare Mater. 2018, 7, 1800899). In addition to the higher drug loading and improved anticancer efficacy with these novel systems, their stability against enzyme digestion can be significantly enhanced through incorporating D-form amino acids.

\subsection{Templates for biomimetic mineralization and nanofabrication}

Upon self-assembly in aqueous solution, polar amino acids are mainly distributed on the self-assembled nanostructures' surface. As indicated above, polar amino acids often play functional roles, such as in catalysis, recognition, sensing, signal transduction, and metal complexation. Given the high stability of many self-assembled peptide nanostructure, they have been widely used as templates for biomimetic mineralization and nanofabrication 
$[108,151-158]$.

Ac- $\mathrm{I}_{3} \mathrm{~K}-\mathrm{NH}_{2}$ nanofibers are very stable and the positively charged Lys residues are projected on their surfaces [108]. Under mild conditions, $\mathrm{Ac}-\mathrm{I}_{3} \mathrm{~K}-\mathrm{NH}_{2}$ nanofibers can induce the sol-gel reaction of TOES and other silica precursors and direct silica deposition along the nanofibers, thus leading to the formation of silica nanomaterials (e.g. nanotubes and string of silica beads) $[108,155,156]$. Their morphologies can be fine-tuned by changing solution conditions (Fig. 6d). These studies would be helpful for understanding the underlying mechanism of silicification in living organisms. In addition, $A c-\mathrm{I}_{3} \mathrm{~K}-\mathrm{NH}_{2}$ nanofibers have been used as templates to construct 1D Pt nanostructures [158]. By combining with inorganic binding peptide TLHVSSY, helical arrays of Pt nanocrystals can be fabricated (Fig. 6d). The continuous 1D Pt nanostructures show reasonably high electrochemical catalytic activity for methanol electro-oxidation. 


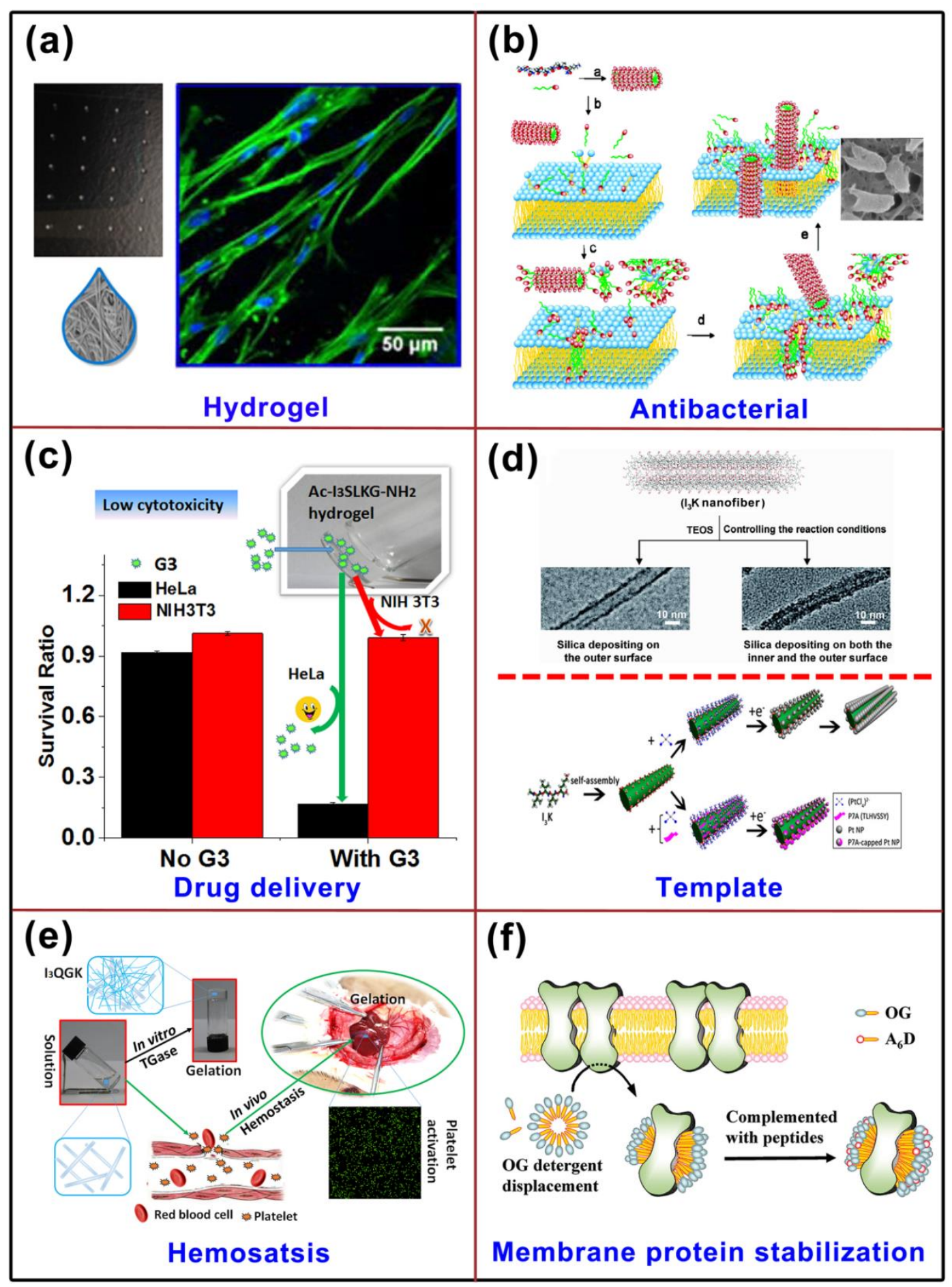

Fig. 6. Exemplary SLP applications. (a) Hydrogels can act as inks for bioprinting, adapted from Ref. [141] with permission of American Chemical Society. (b) The antibacterial mechanism of $\mathrm{Ac}-\mathrm{A}_{9} \mathrm{~K}-\mathrm{NH}_{2}$, adapted from Ref. [131] and [142] with permission of Elsevier Ltd. and American Chemical Society, respectively.

(c) Controllable delivery of an antibacterial peptide G3 from Ac- $\mathrm{I}_{3} \mathrm{SLKG}-\mathrm{NH}_{2}$ hydrogels, reproduced Ref.

[126] with permission of American Chemical Society. (d) Templates for biomimetic silicification and 
nanofabrication, reproduced from Ref. [155] and [158] with permission of American Chemical Society and Nature Publishing Group, respectively. (e) Hemostasis by Ac- $\mathrm{I}_{3} \mathrm{QGK}-\mathrm{NH}_{2}$, reproduced from Ref. [52] with permission of American Chemical Society. (g) Model of rhodopsin stabilization using $A c-\mathrm{A}_{6} \mathrm{D}$, reproduced from Ref. [163] with permission of National Academy of Sciences. Note that cationic SLPs are capped at both termini and anionic ones only capped at $\mathrm{N}$-terminus, and for brevity, Ac- and $-\mathrm{NH}_{2}$ are omitted in some images.

\subsection{Hemostasis}

As indicated above, TGase can induce the hydrogelation of $\mathrm{Ac}-\mathrm{I}_{3} \mathrm{QGK}-\mathrm{NH}_{2}$ [52]. Specifically, we have demonstrated the enzymatic formation of peptide dimers from monomers through intermolecular $\varepsilon$-( $\gamma$-glutamyl)lysine isopeptide bonding. The dimers rapidly self-assemble into flexible and entangled nanofibers, and the coexistence of the original Ac- $\mathrm{I}_{3} \mathrm{QGK}-\mathrm{NH}_{2}$ nanoribbons and the newly created nanofibers is responsible for hydrogelation. As a zymogen circulating naturally in the blood, Factor XIII can be converted into Factor XIIIa (an active TGase) during bleeding. As a result, the peptide solution shows a more rapid and effective in vivo hemostasis (Fig. 6e), relative to other hemostasis methods or materials (e.g. ionic complementary peptide EAK16 [159]). Additionally, the peptide exhibits low cytotoxicity against normal mammalian cells and did not induce non-specific immunological responses. Low cytotoxicity and good biocompatibility of $\mathrm{Ac}-\mathrm{I}_{3} \mathrm{QGK}-\mathrm{NH}_{2}$, together with its rapid and effective hemostasis, endow it with great potential for future clinical hemostasis applications.

\subsection{Membrane protein stabilization}

Zhang et al. have exploited SLPs for stabilizing hydrophobic membrane proteins, 
considering their behavior as both surfactants and proteins [160-165]. More advances in this regard are covered in a review of Zhang [166]. SLPs associate with membrane proteins mainly via mild interactions, which makes them soluble and stable in aqueous solutions (Fig. 6f). Although the exact mechanism remains unclear, it is generally thought that the peptide surfactants work like lipids and can provide a hydrophobic milieu for membrane proteins to accommodate whilst minimizing the risk of protein denaturation. The binding of SLPs to membrane proteins is usually reversible, thus favoring their subsequent characterization, crystallization, and utilization. When SLPs are mixed with conventional detergents, they show improved stabilizing effects on membrane proteins in aqueous solution. The sequence length and the charge type and distribution of SLPs are key factors to be considered in membrane protein stabilization. For example, the mOR103-15 olfactory receptor is expressed much more in a cell-free expression system with the negatively charged $\mathrm{Ac}-\mathrm{A}_{6} \mathrm{D}$ than $\mathrm{DA}_{6}-\mathrm{NH}_{2}$, Ac- $\mathrm{A}_{6} \mathrm{~K}-\mathrm{NH}_{2}$ and $\mathrm{KA}_{6}-\mathrm{NH}_{2}$ do [164].

\section{Conclusions and outlooks}

In deciphering and imitating protein architectures and functions, the self-assembly of short peptides is an effective strategy, given their structural robustness and stability, ease of molecular design and synthesis, and easy establishment of sequence-to-structure relationships. Furthermore, the huge diversity of amino acids in their physiochemical and biological properties endows peptide self-assembly with a great potential for the construction of ordered materials tailored to specific functions. The general physical principles accumulated from the literature, by which proteins fold and function, can be applied to the design of peptide self-assembly. 
To date, a large number of short peptide building blocks, their derivative and analogues have been achieved either through rational design or serendipity. Of them, amphiphilic SLPs are of particular interest due to the integration of the structural characteristics of conventional surfactants into their sequences. Their short length, well-defined hydrophobic and hydrophilic regions, molecular amphiphilicity, and excellent water solubility make it convenient to control their self-assembly behaviors through rational molecular design and modulation of the solution conditions. The generic methods used in molecular design include amino acid substitution, sequence variation, peptide length, amino acid chirality and incorporation of specific amino acids. SLPs have shown application potential in cell culture, antibacterial and anticancer treatments, drug delivery and controlled release, biomimetic mineralization and nanofabrication, hemostasis, and membrane protein stabilization.

Future work on SLPs is not without their challenges. In our opinion, the following steps are worthy of consideration: (1) the design of more SLPs building blocks with novel molecular geometries and functional motifs that retain strong self-assembling ability, (2) the preparation of SLPs hydrogels with tunable mechanical properties and controllable degradation behaviors to mimic native ECM, (3) the self-assembly of SLPs in crowded or confined environments, so that in vivo biological organization can be better understand or imitated, (4) the construction of artificial enzymes by the self-assembly of SLPs to attain strong and stable biological activities, and (5) investigation of the self-assembly process of SLPs and their microscopic and mesoscopic structures by using in situ techniques such as small angle X-ray/neutron scattering (SAXS/SANS), single molecule fluorescence microscopy, super-resolved fluorescence microscopy, and cryo-electron microscopy as well as MD simulations. 
Fortunately, researchers have recently embarked on some of these tasks, such as the self-assembly of amyloid-like peptides in cell milieu, catalytic amyloids self-assembled from short peptides in the presence of $\mathrm{Zn}^{2+}$, and the dynamic process of $\mathrm{Ac}-\mathrm{I}_{3} \mathrm{~K}-\mathrm{NH}_{2}$ self-assembly monitored by STORM super-resolved fluorescence microscopy [47,167,168]. Through addressing these issues many exciting observations and discoveries will be achieved in the coming years. Successes would signify new advances in the understanding and control of novel SLPs biomaterials and pave the way towards more effective applications.

\section{Acknowledgements}

The work is supported by the National Natural Science Foundation of China under grant numbers 21673293, 21573287, 21503275 and U1832108. We also thank the UK Engineering and Physical Science Research Council (EPSRC) and Innovate UK for funding support under EP/F062966/1 and KTP008143.

\section{References}

[1] W. H. Elliott, D. C. Elliott, Biochemistry and molecular biology, Oxford University Press, New York, 2001.

[2] A. M. Lesk, Introduction of protein architecture, Oxford University Press, New York, 2003.

[3] P. C. Ke, M. -A. Sani, F. Ding, A. Kakinen, I. Javed, F. Separovic, T. P. Davis, R. Mezzenga, Implications of peptide assemblies in amyloid diseases, Chem. Soc. Rev. 46 (2017) 6492-6531.

[4] T. P. J. Knowles, M. Vendruscolo, C. M. Dobson, The amyloid state and its association with protein misfolding diseases, Nat. Rev. Mol. Cell Biol. 15 (2014) 384-396.

[5] C. M. Dobson, Protein folding and misfolding, Nature 426 (2003) 884-890. 
[6] C. J. Epstein, R. F. Goldberger, C. B. Anfinsen, The genetic control of tertiary protein structure: studies with model system, Cold Spring Harbor Symp. Quant. Biol. 28 (1963) 439-449.

[7] C. B. Anfinsen, Principles that govern the folding of protein chains, Science 181 (1973) 223-230.

[8] A. Fersht, Structure and mechanism in protein science: a guide to enzyme catalysis and protein folding, W. H. Freeman, New York, 1999.

[9] K. A. Dill, J. L. MacCallum, The protein-folding problem, 50 years on, Science 338 (2012) 1042-1046.

[10] Y. Bai, Q. Luo, J. Liu, Protein self-assembly via supramolecular strategies, Chem. Soc. Rev. 45 (2016) 2756-2767.

[11] Q. Luo, C. Hou, Y. Bai, R. Wang, J. Liu, Protein assembly: versatile approaches to construct highly ordered nanostructures, Chem. Rev. 116 (2016) 13571-13632.

[12] H. Kitagishi, K. Oohora, H. Yamaguchi, H. Sato, T. Matsuo, A. Harada, T. Hayashi, Supramolecular hemoprotein linear assembly by successive interprotein heme-heme pocket interactions, J. Am. Chem. Soc. 129 (2007) 10326-10327.

[13] M. M. C. Bastings, T. F. A. de Greef, J. L. J. van Dongen, M. Merks, E. W. Meijer, Macrocyclization of enzyme-based supramolecular polymers, Chem. Sci. 1 (2010) 79-88.

[14] F. Sakai, G. Yang, M. Weiss, Y. Liu, G. Chen, M. Jiang, Protein crystalline frameworks with controllable interpenetration directed by dual supramolecular interactions, Nat. Commun. 5 (2014) 4634 .

[15] H. Sun, X. Zhang, L. Miao, L. Zhao, Q. Luo, J. Xu, J. Liu, Micelle-induced self-assembling protein nanowires: versatile supramolecular scaffolds for designing the light-harvesting system, ACS Nano 10 (2016) 421-428.

[16] E. N. Salgado, R. J. Radford and F. A. Tezcan, Metal-directed protein self-assembly, Acc. Chem. Res. 43 (2010) 661-672. 
[17] N. P. King, J. B. Bale, W. Sheffler, D. E. McNamara, S. Gonen, T. Gonen, T. O. Yeates, D. Baker, Accurate design of co-assembling multi-component protein nanomaterials, Nature 510 (2014) 103-108.

[18] S. Gonen, F. DiMaio, T. Gonen, D. Baker, Design of ordered two-dimensional array mediated by noncovalent protein-protein interfaces, Science 348 (2015) 1365-1368.

[19] H. Shen, J. A. Fallas, E. Lynch, W. Sheffler, B. Parry, N. Jannetty, J. Decarreau, M. Wagenbach, J. J. Vicente, J. J. Chen, L. Wang, Q. Dowling, G. Oberdorfer, L. Stewart, L. Wordeman, J. De Yoreo, C. Jacobs-Wagner, J. Kollman, D. Baker, De novo design of self-assembling helical protein filaments, Science 362 (2018) 705-709.

[20] E. Gazit, Self-assembled peptide nanostructures: the design of molecular building blocks and their technological utilization, Chem. Soc. Rev. 36 (2007) 1263-1269.

[21] G. Colombo, P. Soto, E. Gazit, Peptide self-assembly at the nanoscale: a challenging target for computational and experimental biotechnology, Trends Biotechnol. 25 (2007) 211-218.

[22] E. Ruoslahti, M. D. Pierschbacher, New perspectives in cell adhesion: RGD and integrins, Science 238 (1987) 491-497.

[23] B. E. Turk, L. L. Huang, E. T. Piro, L. C. Cantley, Determination of protease cleavage site motifs using mixture-based oriented peptide libraries, Nat. Biotechnol. 19 (2001) 661-667.

[24] J. J. Balbach, Y. Ishii, O. N. Antzutkin, R. D. Leapman, N. W. Rizzo, F. Dyda, J. Reed, R. Tycko, Amyloid fibril formation by $A \beta_{16-22}$, a seven-residue fragment of the Alzheimer's $\beta$-amyloid peptide, and structural characterization by solid state NMR, Biochemistry 39 (2000) 13748-13759.

[25] E. Gazit, A possible role for $\pi$-stacking in the self-assembly of amyloid fibrils, FASEB J. 16 (2002) 77-83.

[26] M. Reches, Y. Porat, E. Gazit, Amyloid fibril formation by pentapeptide and tetrapeptide fragments of 
human calcitonin, J. Biol. Chem. 277 (2002) 35475-35480.

[27] C. Lara, N. P. Reynolds, J. T. Berryman, A. Xu, A. Zhang, R. Mezzenga, ILQINS hexapeptide, identified in lysozyme left-handed helical ribbons and nanotubes, forms right-handed helical ribbons and crystals, J. Am. Chem. Soc. 136 (2014) 4732-4739.

[28] M. Reches, E. Gazit, Casting metal nanowires within discrete self-assembled peptide nanotubes, Science 300 (2003) 625-627.

[29] N. Kol, L. Adler-Abramovich, D. Barlam, R. Z. Shneck, E. Gazit, I. Rousso, Self-assembled peptide nanotubes are uniquely rigid bioinspired supramolecular structures, Nano Lett. 5 (2005) 1343-1346.

[30] L. Adler-Abramovich, M. Reches, V. L. Sedman, S. Allen, S. J. B. Tendler, E. Gazit, Thermal and chemical stability of diphenylalanine peptide nanotubes: implication for nanotechnology applications, Langmuir 22 (2006) 1313-1320.

[31] X. Yan, P. Zhu, J. Li, Self-assembly and application of diphenylalanine-based nanostructures, Chem. Soc. Rev. 39 (2010) 1877-1890.

[32] S. Fleming, R. V. Ulijn, Design of nanostructures based on aromatic peptide amphiphiles, Chem. Soc. Rev. 43 (2014) 8150-8177.

[33] K. Tao, A. Levin, L. Adler-Abramovich, E. Gazit, Fmoc-modified amino acids and short peptides: simple bio-inspired building blocks for the fabrication of functional materials, Chem. Soc. Rev. 45 (2016) 3935-3953.

[34] K. Tao, P. Makam, R. Aizen, E. Gazit, Self-assembling peptide semiconductors, Science 358 (2017) eaam9756.

[35] F. Crick, Central dogma of molecular biology, Nature 227 (1970) 561-563.

[36] J. -L. Fauchère, V. Pliška, Hydrophobic parameters $\pi$ of amino-acid side chains from the partitioning 
of N-acetyl-amino-acid amides, Eur. J. Med. Chem. 18 (1983) 369-375.

[37] M. C. J. Wilce, M. -I. Aguilar, M. T. W. Heam, Physicochemical basis of amino acid hydrophobicity scales: evaluation of four new scales of amino acid hydrophobicity coefficients derived from RP-HPLC of peptides, Anal. Chem. 67 (1995) 1210-1219.

[38] D. Voet, J. G. Voet, C.W. Pratt, Fundamentals of biochemistry, John Wiley \& Sons New York, 1999

[39] R. V. Ulijn, A. M. Smith, Designing peptide based nanomaterials, Chem. Soc. Rev. 37 (2008) 664-675.

[40] A. L. Boyle, D. N. Woolfson, De novo designed peptides for biological applications, Chem. Soc. Rev. 40 (2011) 4295-4306.

[41] C. J. Bowerman, B. L. Nilsson, A reductive trigger for peptide self-assembly and hydrogelation, J. Am. Chem. Soc. 132 (2010) 9526-9527.

[42] Z. Yang, G. Liang, L. Wang, B. Xu, Using a kinase/phosphatase switch to regulate a supramolecular hydrogel and forming the supramolecular hydrogel in vivo, J. Am. Chem. Soc. 128 (2006) 3038-3043.

[43] Z. Yang, G. Liang, B. Xu, Enzymatic hydrogelation of small molecules, Acc. Chem. Res. 41 (2008) $315-326$.

[44] Y. Kang, J. Shi, J. Li, D. Yuan, K. A. Alberti, Q. Xu, B. Xu, Pericellular hydrogel/nanonets inhibit cancer cells, Angew. Chem. Int. Ed. 53 (2014) 8104-8107.

[45] J. Zhou, X. Du, B. Xu, Regulating the rate of molecular self-assembly for targeting cancer cells, Angew. Chem. Int. Ed. 55 (2016) 5770-5775.

[46] H. Wang, Z. Feng, Y. Wang, R. Zhou, Z. Yang, B. Xu, Integrating enzymatic self-assembly and mitochondria targeting for selectively killing cancer cells without acquired drug resistance, J. Am. Chem. Soc. 138 (2016) 16046-16055.

[47] H. Wang, Z. Feng, B. Xu, Bioinspired assembly of small molecules in cell milieu, Chem. Soc. Rev. 47 
(2017) 2421-2436.

[48] Z. Feng, T. Zhang, H. Wang, B. Xu, Supramolecular catalysis and dynamic assemblies for medicine, Chem. Soc. Rev. 47 (2017) 6470-6479.

[49] M. Xiao, M. D. Shawkey, N. C. Gianneschi, Melanin-inspired polymeric peptide pigments with tunable sequence-dependent behavior, Chem 3 (2017) 28-30.

[50] A. Lampel, S. A. Mcphee, H. -A. Park, G. G. Scott, S. Humagain, D. R. Hekstra, B. Yoo, P. W. J. M.

Frederix, T. -D. Li, R. R. Abzalimov, S. G. Greenbaum, T. Tuttle, C. Hu, C. J. Bettinger, R. V. Ulijn, Polymeric peptide pigments with sequence-encoded properties, Science 356 (2017) 1064-1068.

[51] M. Griffin, R. Casadio, C. M. Bergamini, Transglutaminases: nature's biological glues, Biochem. J. 368 (2002) 377-396.

[52] C. Chen, Y. Zhang, R. Fei, C. Cao, M. Wang, J. Wang, J. Bai, H. Cox, T. Waigh, J. R. Lu, H. Xu, Hydrogelation of the short self-assembling peptide $\mathrm{I}_{3} \mathrm{QGK}$ regulated by transglutaminase and use for rapid hemostasis, ACS Appl. Mater. Interfaces 8 (2016) 17833-17841.

[53] G. M. Whitesides, J. P. Mathias, C. T. Seto, Molecular self-assembly and nanochemistry: a chemical strategy for the synthesis of nanostructures, Science 254 (1991) 1312-1319.

[54] S. Zhang, Fabrication of novel biomaterials through molecular self-assembly, Nat. Biotechnol. 21 (2003) 1171-1178.

[55] J. Hu, C. Chen, S. Zhang, X. Zhao, H. Xu, X. Zhao, J. R. Lu, Designed antimicrobial and antitumor peptides with high selectivity, Biomacromolecules 12 (2011) 3839-3843.

[56] L. Deng, P. Zhou, Y. Zhao, Y. Wang, H. Xu, Molecular origin of the self-assembled morphological difference caused by varying the order of charged residues in short peptides, J. Phys. Chem. B 118 (2014) 12501-12510. 
[57] T. Takekiyo, L. Wu, Y. Yoshimura, A. Shimizu, T. A. Keiderling, Relationship between hydrophobic interactions and secondary structure stability for trpzip $\beta$-hairpin peptides, Biochemistry 48 (2009) $1543-1552$.

[58] M. F. Perutz, R. Staden, L. Moens, I. D. Baere, Polar zippers, Curr. Biol. 3 (1993) 249-253.

[59] M. F. Perutz, T. Johnson, M. Suzuki, J. T. Finch, Glutamine repeats as polar zippers: their possible role in inherited neurodegenerative diseases, Proc. Natl. Acad. Sci. U. S. A. 91 (1994) 5355-5358.

[60] M. Wang, J. Wang, P. Zhou, J. Deng, Y. Zhao, Y. Sun, W. Yang, D. Wang, Z. Li, X. Hu, S. M. King, S. E. Rogers, H. Cox, T. A. Waigh, J. Yang, J. R. Lu, H. Xu, Nanoribbons self-assembled from short peptides demonstrate the formation of polar zippers between $\beta$-sheets, Nat. Commun. 9 (2019) 5118.

[61] A. Chakrabartty, T. Kortemme, R. L. Baldwin, Helix propensities of the amino acids measured in alanine-based peptides without helix-stabilizing side-chain interactions, Protein Sci. 3 (1994) 843-852.

[62] A. M. Smith, R. J. Williams, C. Tang, P. Coppo, R. F. Collins, M. L. Turner, A. Saiani, R. V. Ulijn, Fmoc-diphenylalanine self assembles to a hydrogel via a novel architecture based on $\pi-\pi$ interlocked $\beta$-sheets, Adv. Mater. 20 (2008) 37-41.

[63] Z. Yang, H. Gu, D. Fu, P. Gao, J. K. Lam, B. Xu, Enzymatic formation of supramolecular hydrogels, Adv. Mater. 16 (2004) 1440-1444.

[64] D. J. Pochan, J. P. Schneider, J. Kretsinger, B. Ozbas, K. Rajagopal, L. Haines, Thermally reversible hydrogels via intramolecular folding and consequent self-assembly of a de novo designed peptide, J. Am. Chem. Soc. 125 (2003) 11802-11803.

[65] P. Zhu, X. Yan, Y. Su, Y. Yang, J. Li, Solvent-induced structural transition of self-assembled dipeptide: from organogels to microcrystals, Chem. - Eur. J. 16 (2010) 3176-3183.

[66] Y. Zhao, L. Deng, J. Wang, H. Xu, J. R. Lu, Solvent controlled structural transition of $\mathrm{KI}_{4} \mathrm{~K}$ 
self-assemblies: from nanotubes to nanofibrils, Langmuir 31 (2015) 12975-12983.

[67] J. P. Schneider, D. J. Pochan, B. Ozbas, K. Rajagopal, L. Pakstis, J. Kretsinger, Responsive hydrogels from the intramolecular folding and self-assembly of a designed peptide, J. Am. Chem. Soc. 124 (2002) $15030-15037$.

[68] B. Ozbas, J. Kretsinger, K. Rajagopal, J. P. Schneider, D. J. Pochan, Salt-triggered peptide folding and consequent self-assembly into hydrogels with tunable modulus, Macromolecules 37 (2004) 7331-7337.

[69] J. D. Hartgerink, E. Beniash, S. I. Stupp, Self-assembly and mineralization of peptide-amphiphile nanofibers, Science 294 (2001) 1684-1688.

[70] J. D. Hartgerink, E. Beniash, S. I. Stupp, Peptide-amphiphile nanofibers: a versatile scaffold for the preparation of self-assembling materials, Proc. Natl. Acad. Sci. U. S. A. 99 (2002) 5133-5138.

[71] S. Zhang, T. Holmes, C. Lockshin, A. Rich, Spontaneous assembly of a self-complementary oligopeptide to form a stable macroscopic membrane, Proc. Natl. Acad. Sci. U. S. A. 90 (1993) 3334-3338. [72] C. A. E. Hauser, S. Zhang, Designer self-assembling peptide nanofiber biological materials, Chem. Soc. Rev. 39 (2010) 2780-2790.

[73] P. Zhou, L. Deng, Y. Wang, J. R. Lu, H. Xu, Different nanostructures caused by competition of intraand inter- $\beta$-sheet interactions in hierarchical self-assembly of short peptides, J. Colloid Interface Sci. 464 (2016) 219-228.

[74] M. J. Pandya, G. M. Spooner, M. Sunde, J. R. Thorpe, A. Rodger, D. N. Woolfson, Sticky-end assembly of a designed peptide fiber provides insight into protein fibrillogenesis, Biochemistry 39 (2000) 8728-8734.

[75] D. Papapostolou, A. M. Smith, E. D. T. Atkins, S. J. Oliver, M. G. Ryadnov, L. C. Serpell, D. N. Woolfson, Engineering nanoscale order into a designed protein fiber, Proc. Natl. Acad. Sci. U. S. A. 104 
(2007) 10853-10858.

[76] E. F. Banwell, E. S. Abelardo, D. J. Adams, M. A. Birchall, A. Corrigan, A. M. Donald, M. Kirkland, L. C. Serpell, M. F. Butler, D. N. Woolfson, Rational design and application of responsive $\alpha$-helical peptide hydrogels, Nat. Mater. 8 (2009) 596-600.

[77] D. N. Woolfson, Z. N. Mahmoud, More than just bare scaffolds: towards multi-component and decorated fibrous biomaterials, Chem. Soc. Rev. 39 (2010) 3464-3479.

[78] C. Wang, Y. Sun, J. Wang, H. Xu, J. R. Lu, Copper(II)-mediated self-assembly of hairpin peptides and templated synthesis of CuS nanowires, Chem. - Asian J. 10 (2015) 1953-1958.

[79] S. N. Dublin, V. P. Conticello, Design of a selective metal ion switch for self-assembly of peptide-based fibrils, J. Am. Chem. Soc. 130 (2008) 49-51.

[80] S. Han, S. Cao, Y. Wang, J. Wang, D. Xia, H. Xu, X. Zhao, J. R. Lu, Self-assembly of short peptide amphiphiles: the cooperative effect of hydrophobic interaction and hydrogen bonding, Chem. - Eur. J. 17 (2011) 13095-13102

[81] P. Zhou, L. Deng, Y. Wang, J. R. Lu, H. Xu, Interplay between intrinsic conformational propensities and intermolecular interactions in the self-assembly of short surfactant-like peptides composed of leucine/isoleucine, Langmuir 32 (2016) 4662-4672.

[82] S. E. Paramonov, H. -W. Jun, J. D. Hartgerink, Self-assembly of peptide-amphiphile nanofibers: the roles of hydrogen bonding and amphiphilic packing, J. Am. Chem. Soc. 128 (2006) 7291-7298.

[83] M. R. Ghadiri, J. R. Granja, R. A. Milligan, D. E. McRee, N. Khazanovich, Self-assembling organic nanotubes based on a cyclic peptide architecture, Nature 366 (1993) 324-327.

[84] D. T. Bong, T. D. Clark, J. R. Granja, M. R. Ghadiri, Self-assembling organic nanotubes, Angew. Chem., Int. Ed. 40 (2001) 988-1011. 
[85] S. Vauthey, S. Santoso, H. Gong, N. Watson, S. Zhang, Molecular self-assembly of surfactant-like peptides to form nanotubes and nanovesicles, Proc. Natl. Acad. Sci. U. S. A. 99 (2002) 5355-5360.

[86] H. Dong, S. E. Paramonov, L. Aulisa, E. L. Bakota, J. D. Hartgerink, Self-assembly of multidomain peptides: balancing molecular frustration controls conformation and nanostructures, J. Am. Chem. Soc. 129 (2007) 12468-12472.

[87] J. Zhang, Y. Zhao, S. Han, C. Chen, H. Xu, Self-assembly of surfactant-like peptides and their applications, Sci. China: Chem. 57 (2014) 1634-1645.

[88] I. W. Hamley, Self-assembly of amphiphilic peptides, Soft Matter 7 (2011) 4122-4138.

[89] X. Zhao, F. Pan, H. Xu, M. Yaseen, H. Shan, C. E. Hauser, S. Zhang, J. R. Lu, Molecular self-assembly and applications of designer peptide amphiphiles, Chem. Soc. Rev. 39 (2010) 3480-3498.

[90] G. A. Silva, C. Czeisler, K. L. Niece, E. Beniash, D. A. Harrington, J. A. Kessler, S. I. Stupp, Neural progenitor cells by high-epitope density nanofibers, Science 303 (2004) 1352-1355.

[91] H. Cui, M. J. Webber, S. I Stupp, Self-assembly of peptide amphiphiles: from molecules to nanostructures to biomaterials, Biopolymers 94 (2010) 1-18.

[92] J. B. Matson, S. I. Stupp, Self-assembling peptide scaffolds for regenerative medicine, Chem. Commun. 48 (2012) 26-33.

[93] M. P. Hendricks, K. Sato, L. C. Palmer, S. I. Stupp, Supramolecular assembly of peptide amphiphiles, Acc. Chem. Res. 50 (2017) 2440-2448.

[94] S. Zhang, Lipid-like self-assembling peptides, Acc. Chem. Res. 45 (2012) 2142-2150.

[95] S. Santoso, W. Hwang, H. Hartman, S. Zhang, Self-assembly of surfactant-like peptides with variable glycine tails to form nanotubes and nanovesicles, Nano Lett. 2 (2002) 687-691.

[96] G. von Maltzahn, S. Vauthey, S. Santoso, S. Zhang, Positively charged surfactant-like peptides 
self-assembly into nanostructures, Langmuir 19 (2003) 4332-4337.

[97] H. Xu, J. Wang, S. Han, J. Wang, D. Yu, H. Zhang, D. Xia, X. Zhao, T. A. Waigh, J. R. Lu, Hydrophobic-region-induced transitions in self-assembled peptide nanostructures, Langmuir 25 (2009) $4115-4123$

[98] V. Castelletto, D. R. Nutt, I. W. Hamley, S. Bucak, Ç. Cenker, U. Olsson, Structure of single-wall peptide nanotubes: in situ flow aligning X-ray diffraction, Chem. Commun. 46 (2010) 6270-6272.

[99] J. Wang, S. Han, G. Meng, H. Xu, D. Xia, X. Zhao, R. Schweins, R.; Lu, J. R. Dynamic self-assembly of surfactant-like peptides $\mathrm{A}_{6} \mathrm{~K}$ and $\mathrm{A}_{9} \mathrm{~K}$, Soft Matter 5 (2009) 3870-3878.

[100] U. Khoe, Y. Yang, S. Zhang, Self-assembly of nanodonut structure from a cone-shaped designer lipid-like peptide surfactant, Langmuir 25 (2009) 4111-4114.

[101] A. J. van Hell, C. I C. A. Costa, F. M. Flesch, M. Sutter, W. Jiskoot, D. J. A. Crommelin, W. E. Hennink and E. Mastrobattista, Self-assembly of recombinant amphiphilic oligopeptides into vesicles, Biomacromolecules 8 (2007) 2753-2761.

[102] C. A. E. Hauser, R. Deng, A. Mishra, Y. Loo, U. Khoe, F. Zhuang, D. W. Cheong, A. Accardo, M. B. Sullivan, C. Riekel, J. Y. Ying, U. A. Hauser, Natural tri- to hexapeptides self-assemble in water to amyloid $\beta$-type fiber aggregates by unexpected $\alpha$-helical intermediate structures, Proc. Natl. Acad. Sci. U. S. A. 108 (2011) 1361-1366.

[103] A. Mishra, Y. Loo, R. Deng, Y. J. Chuah, H. T. Hee, J. Y. Ying, C. A. E. Hauser, Ultrasmall natural peptides self-assemble to strong temperature-resistant helical fibers in scaffolds suitable for tissue engineering, Nano Today 6 (2011) 232-239.

[104] Y. Zhao, J. Wang, L. Deng, P. Zhou, S. Wang, Y. Wang, H. Xu, J. R. Lu, Tuning the self-assembly of short peptides via sequence variations, Langmuir 29 (2013) 13457-13464. 
[105] Y. Zhao, L. Deng, W. Yang, D. Wang, E. Pambou, Z. Lu, Z. Li, J. Wang, S. King, S. Rogers, H. Xu, J.

R. Lu, Tuning one-dimensional nanostructures of bola-like peptide amphiphiles by varying the hydrophilic amino acids, Chem.- Eur. J. 22 (2016) 11394-11404.

[106] E. R. da Silva, W. A. Alves, V. Castelletto, M. Reza, J. Ruokolaine, R. Hussain, I. W. Hamley, Self-assembly pathway of peptide nanotubes formed by a glutamatic acid-based bolaamphiphile, Chem. Commun. 51 (2015) 11634-11637.

[107] I. W. Hamley, S. Burholt, J. Hutchinson, V. Castelletto, Shear alignment of bola-amphiphilic arginine-coated-peptide nanotubes, Biomacromolecules 18 (2017) 141-149

[108] H. Xu, Y. Wang, X. Ge, S. Han, S. Wang, P. Zhou, H. Shan, X. Zhao, J. R. Lu, Twisted nanotubes formed from ultrashort amphiphilic peptide $\mathrm{I}_{3} \mathrm{~K}$ and their templating for the fabrication of silica nanotubes, Chem. Mater 22 (2010) 5165-5173.

[109] A. Nagai, Y. Nagai, H. Qu, S. Zhang, Dynamic behaviors of lipid-like self-assembling peptide $A_{6} D$ and $\mathrm{A}_{6} \mathrm{~K}$ nanotubes, J. Nanosci. Nanotechnol. 7 (2007) 2246-2252.

[110] S. J. Yang, S. Zhang, Self-assembling behavior of designer lipid-like peptides, Supramol. Chem. 18 (2006) 389-396.

[111] S. Han, W. Xu, M. Cao, J. Wang, D. Xia, H. Xu, X. Zhao, J. R. Lu, Interfacial adsorption of cationic peptide amphiphiles: a combined study of in situ spectroscopic ellipsometry and liquid AFM, Soft Matter 8 (2012) 645-652.

[112] I. W. Hamley, A. Dehsorkhi, V. Castelletto, Self-assembled arginine-coated peptide nanosheets in water, Chem. Commun. 49 (2013) 1850-1852.

[113] V. Castelletto, R. M. Gouveia, C. J. Connon, I. W. Hamley, J. Seitsonen, A. Nykänen, J. Ruokolainen, Alanine-rich amphiphilic peptide containing the RGD cell adhesion motif: a coating material for human 
fibroblast attachment and culture, Biomater. Sci. 2 (2014) 362-369.

[114] Y. Zhao, W. Yang, D. Wang, J. Wang, Z. Li, X. Hu, S. King, S. Rogers, J. R. Lu, H. Xu, Controlling nanotube diameters self-assembled from designed peptide bolaphiles, Small 14 (2018) e1703216.

[115] H. Cui, A. G. Cheetham, E. T. Pashuck, S. I. Stupp, Amino acid sequence in constitutionally isomeric tetrapeptide amphiphiles dictates architecture of one-dimensional nanostructures, J. Am. Chem. Soc. 136 (2014) 12461-12468.

[116] R. Nagarajan, Molecular packing parameter and surfactant self-assembly: the neglected role of the surfactant tail, Langmuir 18 (2002) 31-38.

[117] M. Wang, P. Zhou, J. Wang, Y. Zhao, H. Ma, J. R. Lu, H. Xu, Left or right: how does amino acid chirality affect the handedness of nanostructures self-assembled from short amphiphilic peptides? J. Am. Chem. Soc. 139 (2017) 4185-4194.

[118] S. Marchesan, C. D. Easton, F. Kushkaki, L. Waddington, P. G. Hartley, Tripeptide self-assembled hydrogels: unexpected twists of chirality, Chem. Commun. 48 (2012) 2195-2197.

[119] S. Marchesan, C. D. Easton, K. E. Styan, L. J. Waddington, F. Kushkaki, L. Goodall, K. M. McLean, J. S. Forsythe, P. G. Hartley, Chirality affects at each amino acid position on tripeptide self-assembly into hydrogel biomaterials, Nanoscale 6 (2014) 5172-5180.

[120] S. Marchesan, K. E. Styan, C. D Easton, L. Waddington, A. V. Vargiu, Higher and lower supramolecular orders for the design of self-assembled heterochiral tripeptide hydrogel biomaterials, J. Mater. Chem. B 3 (2015) 8123-8132.

[121] A. V. Vargiu, D. Iglesias, K. E. Styan, L. J. Waddington, C. D. Easton, S. Marchesan, Design of a hydrophobic tripeptide that self-assembles into amphiphilic superstructures forming a hydrogel biomaterial, 
Chem. Commun. 52 (2016) 5912-5915.

[122] S. Lin, Y. Li, B. Li, Y. Yang, Control of the handedness of self-assemblies of dipeptides by the chirality of phenylalanine and steric hindrance of phenylglycine, Langmuir 32 (2016) 7420-7426.

[123] Q. Xing, J. Zhang, Y. Xie, Y. Wang, W. Qi, H. Rao, R. Su, Z. He, Aromatic motifs dictate nanohelix handedness of tripeptides, ACS Nano 12 (2018) 12305-12314.

[124] A. M. Garcia, D. Iglesias, E. Parisi, K. E. Styan, L. J. Waddington, C. Deganutti, R. De Zorzi, M. Grassi, M. Melchionna, A. V. Vargiu, S. Marchesan, Chirality effects on peptide self-assembly unraveled from molecules to materials, Chem 4 (2018) 1-15.

[125] C. Cao, M. Cao, H. Fan, D. Xia, H. Xu, J. R. Lu, Redox modulated hydrogelation of a self-assembling short peptide amphiphile, Chin. Sci. Bull. 57 (2012) 4296-4303.

[126] C. Chen, Y. Zhang, Z. Hou, X. Cui, Y. Zhao, H. Xu, Rational design of short peptide-based hydrogels with MMP-2 responsiveness for controlled anticancer peptide delivery, Biomacromolecules 18 (2017) 3563-3571.

[127] G. Wei, Z. Su, N. P. Reynolds, P. Arosio, I. W. Hamley, E. Gazit, R. Mezzenga, Self-assembling peptide and protein amyloids: from structure to tailored function in nanotechnology, Chem. Soc. Rev. 46 (2017) 4661-4708.

[128] S. Toledano, R. J. Williams, V. Jayawarna, R. V. Ulijn, Enzyme-triggered self-assembly of peptide hydrogels via reversed hydrolysis, J. Am. Chem. Soc. 128 (2006) 1070-1071.

[129] R. J. Williams, A. M. Smith, R. Collins, N. Hodson, A. K. Das, R. V. Ulijn, Enzyme-assisted self-assembly under thermodynamic control, Nat. Nanotechnol. 4 (2009) 19-24.

[130] M. Zelzer, S. J. Todd, A. R. Hirst, T. O. McDonald, R. V. Ulijn, Enzyme responsive materials: design strategies and future developments, Biomater. Sci. 1 (2013) 11-39. 
[131] C. Chen, J. Hu, S. Zhang, P. Zhou, X. Zhao, H. Xu, X. Zhao, M. Yaseen, J. R. Lu, Molecular mechanisms of antibacterial and antitumor actions of designed surfactant-like peptides, Biomaterials 33 (2012) 592-603.

[132] J. Bai, C. Chen, J. Wang, Y. Zhang, H. Cox, J. Zhang, Y. Wang, J. Penny, T. Waigh, J. R. Lu, H. Xu, Enzymatic regulation of self-assembling peptide $\mathrm{A}_{9} \mathrm{~K}_{2}$ nanostructures and hydrogelation with highly selective antibacterial activities, ACS Appl. Mater. Interfaces 8 (2016) 15093-15102.

[133] E. C. Wu, S. Zhang, C. A. E. Hauser, Self-assembling peptides as cell-interactive scaffolds, Adv. Funct. Mater. 22 (2012) 456-468.

[134] Y. Loo, S. Zhang, C. A. E. Hauser, From short peptides to nanofibers to macromolecular assemblies in biomedicine, Biotechnol. Adv. 30 (2012) 593-603.

[135] S. Maude, E. Ingham, A. Aggeli, Biomimetic self-assembling peptides as scaffolds for soft tissue engineering, Nanomedicine (London, U. K.) 8 (2013) 823-847.

[136] J. P. Jung, J. Z. Gasiorowski, J. H. Collier, Fibrillar peptide gels in biotechnology and biomedicine, Biopolymers 94 (2010) 49-59.

[137] J. H. Collier, J. S. Rudra, J. Z. Gasiorowski, J. P. Jung, Multi-component extracellular matrices based on peptide self-assembly, Chem. Soc. Rev. 39 (2010) 3413-3424.

[138] C. Yan, D. J. Pochan, Rheological properties of peptide-based hydrogels for biomedical and other applications, Chem. Soc. Rev. 39 (2010) 3528-3540.

[139] J. B. Matson, S. I. Stupp, Self-assembling peptide scaffolds for regenerative medicine, Chem. Commun. 48 (2012) 26-33.

[140] G. Fichman, E. Gazit, Self-assembly of short peptides to form hydrogels: design of building blocks, physical properties and technological applications, Acta Biomater. 10 (2014) 1671-1682. 
[141] Y. Loo, A. Lakshmanan, M. Ni, L. L. Toh, S. Wang, C. A. E. Hauser, Peptide bioink: self-assembling nanofibrous scaffolds for three-dimensional organotypic cultures, Nano Lett. 15 (2015) 6919-6925.

[142] C. Chen, F. Pan, S. Zhang, J. Hu, M. Cao, J. Wang, H. Xu, X. Zhao, J. R. Lu, Antibacterial activities of short designer peptides: a link between propensity for nanostructuring and capacity for membrane destabilization, Biomacromolecules 11 (2010) 402-411.

[143] A. Dehsorkhi, V. Castelletto and I. W. Hamley, J. Seitsonen, J. Ruokolainen, Interaction between a cationic surfactant-like peptide and lipid vesicles and its relationship to antimicrobial activity, Langmuir 29 (2013) 14246-14253.

[144] L. Liu, K. Xu, H. Wang, P. K. J. Tan, W. Fan, S. S. Venkatraman, L. Li, Y. -Y. Yang, Self-assembled cationic peptide nanoparticles as an efficient antimicrobial agent, Nat. Nanotechnol. 4 (2009) 457-463.

[145] Y. -C. Lin, Y. F. Lim, E. Russo, P. Schneider, L. Bolliger, A. Edenharter, K. -H. Altmann, C. Halin, J. A. Hiss, G. Schneider, Multidimensional design of anticancer peptides, Angew. Chem. Int. Ed. 54 (2015) $10370-10374$.

[146] C. D. Fjell, J. A. Hiss, R. E. W. Hancock, G. Schneider, Designing antimicrobial peptides: form follows function, Nat. Rev. Drug Discovery 11 (2012) 37-51.

[147] H. Xu, C. Chen, J. Hu, P. Zhou, P. Zeng, C. Cao, J. R. Lu, Dual modes of antitumor action of an amphiphilic peptide $\mathrm{A}_{9} \mathrm{~K}$, Biomaterials 34 (2013) 2731-2737.

[148] D. G. Fatouros, D. A. Lamprou, A. J. Urquhart, S. N. Yannopoulos, I. S. Vizirianakis, S. Zhang, S. Koutsopoulos, Lipid-like self-assembling peptide nanovesicles for drug delivery, ACS Appl. Mater. Interfaces 6 (2014) 8184-8189.

[149] C. Karavasili, M. Spanakis, D. Papagiannopoulou, I. S. Vizirianakis, D. G. Fatouros, S. Koutsopoulos, Bioactive self-assembling lipid-like peptides as permeation enhancers for oral drug delivery, J. Pharm. Sci. 
104 (2015) 2304-2311.

[150] Q. Wang, X. Zhang, J. Zheng, D. Liu, Self-assembled peptide nanotubes as potential nanocarriers for drug delivery, RSC Adv. 4 (2014) 25461- 25469.

[151] V. M. Yuwono, J. D. Hartgerink, Peptide amphiphile nanofibers template and catalyze silica nanotube formation, Langmuir 23 (2007) 5033-5038.

[152] E. Pouget, E. Dujardin, A. Cavalier, A. Moreac, C. Valéry, V. Marchi-Artzner, T. Weiss, A. Renault, M. Paternostre, F. Artzner, Hierarchical architectures by synergy between dynamical template self-assembly and biomineralization, Nat. Mater. 6 (2007) 434-439.

[153] H. Acar, R. Garifullin, M. O. Guler, Self-assembled template-directed synthesis of one-dimensional silica and titania nanostructures, Langmuir 27 (2011) 1079-1084.

[154] A. Dehsorkhi, I. W. Hamley, Silica templating of a self-assembling peptide amphiphile that forms nanotapes, Soft Matter. 10 (2014) 1660-1664.

[155] S. Wang, X. Ge, J. Xue, H. Fan, L. Mu, Y. Li, H. Xu, J. R. Lu, Mechanistic processes underlying biomimetic synthesis of silica nanotubes from self-assembled ultrashort peptide templates, Chem. Mater. 23 (2011) 2466-2474.

[156] S. Wang, J. Xue, X. Ge, H. Fan, H. Xu, J. R. Lu, Biomimetic synthesis of silica nanostructures with controllable morphologies and sizes through interfacial interactions, Chem. Commun. 48 (2012) 9415-9417.

[157] S. Wang, Q. Cai, M. Du, J. Xue, H. Xu, Synthesis of 1D silica nanostructures with controllable sizes based on short anionic peptide self-assembly, J. Phys. Chem. B 119 (2015) 12059-12065.

[158] K. Tao, J. Wang, Y. Li, D. Xia, H. Shan, H. Xu, J. R. Lu, Short peptide-directed synthesis of one-dimensional platinum nanostructures with controllable morphologies, Sci. Rep. 3 (2013) 2565. 
[159] Z. Luo, S. Wang, S. Zhang, Fabrication of self-assembling D-form peptide nanofiber scaffold d-EAK16 for rapid hemostasis, Biomaterials 32 (2011) 2013-2020.

[160] J. I. Yeh, S. Du, A. Tordajada, J. Paulo, S. Zhang, Peptergent: Peptide detergents that improve stability and functionality of a membrane protein, glycerol-3-phosphate dehydrogenase, Biochemistry 44 (2005) 16912-16919.

[161] P. Kiley, X. Zhao, M. Vaughn, M. A. Baldo, B. D. Bruce, S. Zhang, Self-assembling peptide detergents stabilize isolated photosystem I on a dry surface for an extended time, PLoS Biol. 3 (2005) 1180-1186.

[162] K. Matsumoto, M. Vaughn, B. D. Bruce, S. Koutsopoulos, S. Zhang, Designer peptide surfactants stabilize functional photosystem-I membrane complex in aqueous solution for extended time, J. Phys. Chem. B 113 (2009) 75-83.

[163] X. Zhao, Y. Nagai, P. J. Revees, P. Kiley, H. G. Khorana, S. Zhang, Designer short peptide surfactants stabilize G protein-coupled receptor bovine rhodopsin, Proc. Natl. Acad. Sci. U. S. A. 103 (2006) 17707-17712.

[164] X. Wang, K. Corin, P. Baaske, C. J. Wienken,; M. Jerabek-Willemsen, S. Duhr, D. Braun, S. Zhang, Peptide surfactants for cell-free production of functional G protein-coupled receptors, Proc. Natl. Acad. Sci. U. S. A. 108 (2011) 9049-9054.

[165] K. Corin, P. Baaske, D. B. Ravel, J. Song, E. Brown, X. Wang, C. J. Wienken, M. Jerabek-Willemsen, S. Duhr, Y. Luo, D. Braun, S. Zhang, Designer lipid-like peptides: a class of detergents for studying functional olfactory receptors using commercial cell-free systems, PLoS One 6 (2011) e25067. [166] S. Koutsopoulos, L. Kaiser, H. M. Eriksson, S. Zhang, Designer peptide surfactants stabilize diverse functional membrane proteins, Chem. Soc. Rev. 41 (2012) 1721-1728. 
[167] C. M. Rufo, Y. S. Moroz, O. V. Moroz, J. Stöhr, T. A. Smith, X. Hu, W. F. DeGrado, I. V. Korendovych, Short peptides self-assemble to produce catalytic amyloids, Nat. Chem. 6 (2014) 303-309.

[168] H. Cox, P. Georgiades, H. Xu, T. A. Waigh, J. R. Lu, Self-assembly of mesoscopic peptide surfactant fibrils investigated by STORM super-resolution fluorescence microscopy, Biomacromolecules 18 (2017) 3481-3491. 